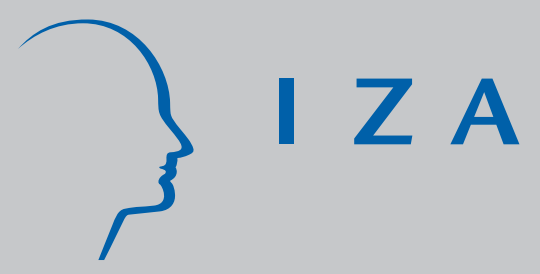

IZADP No. 4080

\title{
Other-Regarding Preferences and Leadership Styles
}

Martin G. Kocher

Ganna Pogrebna

Matthias Sutter

March 2009 


\title{
Other-Regarding Preferences and Leadership Styles
}

\author{
Martin G. Kocher \\ University of Munich \\ Ganna Pogrebna \\ Columbia University \\ Matthias Sutter \\ University of Innsbruck, \\ University of Gothenburg and IZA
}
Discussion Paper No. 4080
March 2009

\author{
IZA \\ P.O. Box 7240 \\ 53072 Bonn \\ Germany \\ Phone: +49-228-3894-0 \\ Fax: +49-228-3894-180 \\ E-mail: iza@iza.org
}

\begin{abstract}
Any opinions expressed here are those of the author(s) and not those of IZA. Research published in this series may include views on policy, but the institute itself takes no institutional policy positions.

The Institute for the Study of Labor (IZA) in Bonn is a local and virtual international research center and a place of communication between science, politics and business. IZA is an independent nonprofit organization supported by Deutsche Post Foundation. The center is associated with the University of Bonn and offers a stimulating research environment through its international network, workshops and conferences, data service, project support, research visits and doctoral program. IZA engages in (i) original and internationally competitive research in all fields of labor economics, (ii) development of policy concepts, and (iii) dissemination of research results and concepts to the interested public.
\end{abstract}

IZA Discussion Papers often represent preliminary work and are circulated to encourage discussion. Citation of such a paper should account for its provisional character. A revised version may be available directly from the author. 
IZA Discussion Paper No. 4080

March 2009

\section{ABSTRACT \\ Other-Regarding Preferences and Leadership Styles ${ }^{*}$}

We use a laboratory experiment to examine whether and to what extent other-regarding preferences of team leaders influence their leadership style in choice under risk. We find that leaders who prefer efficiency or report high levels of selfishness are more likely to exercise an autocratic leadership style by ignoring preferences of the other team members. Yet, inequity aversion has no significant impact on leadership styles. Elected leaders have a higher propensity than exogenously assigned leaders to use a democratic leadership style by reaching team consensus. Male leaders and leaders influenced by group membership tend to employ a democratic leadership style.

JEL Classification: $\quad$ C91, C92, D70, D81

Keywords: leadership style, other-regarding preferences, unobserved heterogeneity

Corresponding author:

Matthias Sutter

University of Innsbruck

Department of Public Finance

Universitaetsstrasse 15/4

A-6020 Innsbruck

Austria

E-mail: matthias.sutter@uibk.ac.at

\footnotetext{
* We are grateful to Stefan Trautmann and Jennifer Logg for many insightful comments. We thank the attendees at the 2007 World Meeting of the Economic Science Association in Rome and the participants at the research seminars at Columbia University in New York (December 2008) and the London School of Economics in London (March 2009) for many helpful suggestions. We also thank the Austrian Science Foundation (Fonds zur Förderung der wissenschaftlichen Forschung in Österreich, Project P16617) for financial support.
} 


\section{OTHER-REGARDING PREFERENCES AND LEADERSHIP STYLES}

\section{INTRODUCTION}

Leadership style and the effectiveness of interactions between leaders and their subordinates are important determinants of team success in any hierarchical organization. Dependent on the way in which leaders exercise their authority, several studies in economics, psychology and management identify two major leadership styles: an autocratic and a democratic style (e.g., Lewin et al., 1939; Rotemberg and Saloner, 1993). While leader's decisions are binding for the whole team irrespective of the leadership style, autocratic leaders allow for only a minimal team participation in the decision making process and sometimes even ignore the opinions of their subordinates (Knott, 2001). In contrast, democratic leaders seek advice from their subordinates and try to reach consensus within their teams (e.g., Hollander, 1986; Rotemberg and Saloner, 1993).

In this paper we explore how leadership styles are affected by other-regarding preferences of leaders. Since leaders' decisions have consequences for all team members, whether and to what extent leaders take into account preferences and opinions of other team members might influence leaders' decision making. Therefore, it seems straightforward to conjecture that other-regarding preferences may have an impact on a leadership style. For example, leaders who are strongly motivated by efficiency concerns (e.g., Charness and Rabin, 2002 and 2005) are likely to be more goal-oriented. Due to this, these leaders might be less inclined to consider the possible outcomes of their decisions for the other team members (relative to the outcomes for themselves). Such leaders may have a high propensity to opt for an autocratic leadership style. In contrast, leaders who are inequality averse (e.g., Fehr and Schmidt, 1999; Bolton and Ockenfels, 2000) may be more prone to accommodate preferences of other team members. Such leaders may be likely to opt for a democratic leadership style.

We design an experiment where teams of three receive a sequence of risky lottery pairs which could be thought of as alternative risky projects. The task of the team is to choose one lottery from each lottery pair. The lotteries yield different payoffs as well as risk coefficients for leaders and the other members of the team (henceforth ordinary players).

After a team is presented with a lottery pair choice, all team members (including the leader) have an opportunity to vote for their preferred lottery. However, the team leader makes a final 
and binding decision after having observed other team members' preferences presented as the team majority decision. By choosing an alternative that contradicts the team majority decision, a leader makes a decision consistent with an autocratic leadership style (i.e., an autocratic decision). By confirming the team voting result, a leader makes a decision consistent with a democratic leadership style (i.e., a democratic decision). By extending the approach of Engelmann and Strobel (2004), we identify individual other-regarding preferences of leaders and determine the impact of other-regarding preferences on leaders' choices. We also explore whether individual demographic characteristics, motivation of leaders, and team performance influence the choice of a leadership style.

Our experimental design offers a new framework for research on leadership styles and contributes to existing literature in the following ways. First, studies on leadership styles primarily concentrate on the relative comparison of autocratic and democratic styles by exogenously manipulating leadership styles as treatment variables (e.g., Van Vugt et al., 2004). However, team leaders not only have flexibility in choosing and following a particular style, but may also adopt situational leadership by switching between different styles under different circumstances.

In our experiment, leadership style is endogenously determined. Leaders have an opportunity to choose repeatedly between an autocratic and a democratic style. This allows us to examine whether leaders use one style consistently throughout the experiment or opt for situational leadership. In addition, we can compare the profitability of autocratic and democratic leadership for teams as a whole as well as for leaders and ordinary players separately.

We also investigate whether leadership style depends on the way in which the leader is appointed. Organizations differ with respect to how they recruit leaders (e.g., CEOs or upper and mid-level managers). Sometimes teams have an opportunity to choose leaders endogenously (by voting one of the team members to be a leader). For example, academic department heads are appointed by faculty vote and CEOs of several corporations are elected by executive boards. In other cases, leaders are appointed exogenously. Our experiment incorporates two treatments. In one treatment, leaders are exogenously determined by a random draw. In the other treatment, leaders are endogenously elected by all team members. Therefore, our design allows us to check 
whether endogenously elected leaders are more likely to opt for the democratic style than exogenously assigned leaders.

Second, our approach differs from the economics literature on leading by example. To date, leadership has been studied predominantly in the context of voluntary contribution games or charitable giving where leadership can be taken over by someone setting a good example of being cooperative or generous. Several theoretical and experimental studies have shown that leadership through setting a good example can increase cooperation in groups since followers tend to reciprocate the leader's behavior in their choices (Vesterlund, 2003; Potters et al., 2005, 2007; Andreoni, 2006; Komai et al., 2007; Güth et al., 2007; Gächter et al., 2008). Even though leading by example is important in organizations, especially in case of informal leadership, this literature does not explore how leaders make decisions in hierarchical organizations when leaders have a formal authority to make binding decisions for the whole team.

Apart from considering leaders with formal authority, our design also contributes to the economics literature on leadership because it examines decision making under risk rather than decisions in a risk-free environment. Though deterministic settings have important implications for team work, leaders and teams often face risk and uncertainty in their daily activities. Therefore, decision making under risk is a natural environment for studying leadership styles.

Third, since the choice of a leadership style may depend on a leader's desire to accommodate preferences of the other group members, motives other than self-interest may significantly influence leaders' decisions. By examining the impact of other-regarding preferences on leadership styles, we bridge the literature on leadership and research on otherregarding preferences.

In our experiment, a team leader is essentially a dictator. Therefore, our research question is related to situations where a dictator determines an allocation of a monetary amount between herself and one other player (e.g., Forsythe et al., 1994; Bolton et al., 1998) as well as among several other players (e.g., Engelmann and Strobel, 2004; Bolton and Ockenfels, 2006; Fehr et al., 2006). Yet, in our setting, leadership is qualitatively different from dictatorship in a dictator game because the leader receives information about other players' preferences prior to making a decision. Furthermore, in our experiment leaders make decisions in a stochastic rather than a deterministic setting. 
Fourth, our research extends the emerging literature on how group membership influences individual behavior (Charness et al., 2007; Chen and Li, forthcoming; Sutter, forthcoming). ${ }^{1}$ In our design, experimental participants select lotteries from lottery pairs in both an individual decision making task and in a team decision making task. This allows us to study whether participants change their individual preferences when making decisions in a team. Controlling for individual preferences allows us to determine the impact of team membership on individual choices. This also gives us an opportunity to investigate whether team membership affects leaders and ordinary players differently.

We find that the majority of leaders adopt situational leadership rather than consistently follow one leadership style. While leaders make democratic decisions in the majority of cases, there is a considerable heterogeneity in leaders' individual propensities to make autocratic and democratic decisions. Although exogenously assigned and endogenously elected leaders are equally likely to adopt any of the two available leadership styles in the aggregate, the manner in which leaders are assigned has important implications on their behavior. Endogenously elected leaders are significantly more likely to follow the team majority decision even when their own preference differs from the team preference. We also find that leaders make autocratic decisions more often when they disagree with the rest of the team.

Autocratic and democratic decisions appear to be equally profitable for teams as a whole. However, while leaders receive essentially the same payoff from autocratic and democratic decisions, ordinary players earn significantly more from democratic than from autocratic decisions.

More importantly, we find that other-regarding preferences influence the choice of leadership style. Leaders who care about efficiency are more likely to make autocratic rather than democratic decisions. Leaders who report high levels of selfishness (according to a selfreported measure of other-regarding preferences) are more likely to overrule their teams.

\footnotetext{
${ }^{1}$ In a more general sense, this paper is related to the literature on decision making in small teams (e.g., Cason and Mui, 1997; Bornstein and Yaniv, 1998; Bone et al., 1999; Cooper and Kagel, 2005). While several studies focus on decision making in a risky environment, the common approach in this literature is to allow all team members the same decision power. In our experiment, the leader has formal authority to make binding decisions for the whole team, while ordinary players can only express their preferences and have no further influence on the leader's decision.
} 
However, inequity aversion does not appear to have a significant impact on the likelihood of autocratic decisions.

The data also indicate a gender effect: women appear more likely to make autocratic than democratic decisions compared with men. In general, our econometric estimations reveal that individual unobserved heterogeneity plays an important role in leaders' choices to confirm or alter team majority decisions.

The remainder of this paper is organized as follows. Section 2 describes the experimental design, laboratory procedures and presents our theoretical hypotheses. Section 3 presents the experimental results, obtained by means of non-parametric comparisons as well as econometric estimations. Section 4 concludes by discussing our findings as well as possible implications.

\section{The Experiment: Design, Procedure, And Hypotheses}

\subsection{EXPERIMENTAL DESIGN}

The experiment incorporates two main experimental tasks: (i) an individual task and (ii) a team task. Participants also receive an additional task. This task is (iii) an other-regarding preferences elicitation procedure. In the two main experimental tasks, we elicit individual and team preferences of participants over several pairs of risky lotteries described below. In the additional task, we use the design of Engelmann and Strobel (2004) - henceforth denoted as E\&S procedure - in order to determine the relative importance of different other-regarding motives for the behavior of experimental participants. ${ }^{2}$

In this subsection, we first explain the design of the lottery pairs that we have used in the two main experimental tasks. Then, we proceed by describing the individual task, the team task, and the E\&S procedure.

\subsubsection{DESIGN OF EXPERIMENTAL LOTTERIES}

We design 17 pairs of lotteries. Each lottery provides two possible monetary allocations for a team of three players. One member of the team is assigned the type of the leader and the other two members are assigned the types of ordinary players. ${ }^{3}$

\footnotetext{
${ }^{2}$ Sample experimental instructions are provided in the Supplementary Material (Appendix A).

${ }^{3}$ Differences between types as well as type-determination procedures are described in Subsection 2.1.3.
} 
Each lottery pair offers a choice between two lotteries with different expected payoffs as well as different risk coefficients for leaders and ordinary players. In other words, leaders and ordinary players have different payoff schemes within the same lottery choice. In the majority of lotteries, the leader receives a higher payoff than ordinary players if this lottery yields its highest possible outcome. If the lottery provides its lowest possible outcome, the leader receives a lower payoff than each of the ordinary players. The intuition for this is based on the system of rewards and punishments for leaders in hierarchical organizations. When the work of the team produces a successful outcome, the leader is usually rewarded; otherwise, the leader is punished, e.g., by being sacked.

Since leaders and ordinary players have different payoff schemes, in each lottery pair players of different types may opt for different alternatives. In other words, leaders and ordinary players might have opposing preferences. Table 1 shows the lottery pairs used in the experiment. Dependent on potential sources of conflict between preferences of leaders and ordinary players, lottery pairs in our experiment can be partitioned into four blocks:

- Block 1: Determination lottery pairs;

- Block 2: Consideration lottery pairs;

- Block 3: Divergence lottery pairs;

- Block 4: Seesaw lottery pairs.

\section{[INSERT Table 1 HERE]}

Panel [A] of Table 1 presents Determination lottery pairs (lottery pairs 1-6). ${ }^{4}$ In each of these lottery pairs, both lotteries (for simplicity of presentation identified in Table 1 as either A or B) yield the same expected payoff to the ordinary player. However, in every Determination lottery pair, lottery B has a higher risk coefficient for the ordinary player than lottery A. At the same time, lottery A yields a higher expected payoff to the leader than lottery B. Yet, for the leader, lottery A also has a higher risk coefficient than lottery B. Therefore, in Determination lottery pairs, leaders and ordinary players do not have an apparent reason to choose different

\footnotetext{
${ }^{4}$ All lotteries in our experiment offer one payoff with probability $1 / 3$ and the other payoff with probability 2/3. Keeping the probabilities fixed across lotteries simplified the task for the participants. In addition, recent studies have found robust evidence that at these probabilities, non-linear probability weighting is least likely to occur (e.g., Wu et al., 2004).
} 
alternatives if they consider expected payoffs of the lotteries. Leaders may determine their preferred lottery in each lottery pair without taking into account the preferences of the ordinary players since both lotteries yield the same expected payoff to the ordinary players. Nevertheless, opposing preferences may arise from the differences in risk coefficients. In lottery pairs of this block, leaders may choose lottery A because it yields a higher expected payoff while ordinary players may opt for lottery B because it has a lower risk coefficient.

Consideration lottery pairs are depicted in panel [B] of Table 1. In each of these lottery pairs a leader receives the same expected payoff from both lotteries but faces lower risk from choosing lottery B. Ordinary players have a different payoff structure. In lottery pair 7 (8), they decide between a relatively risky lottery A (B) with a relatively high expected payoff and a relatively safe lottery B (A) with a relatively low expected payoff. In lottery pair 9, ordinary players choose between a relatively risky lottery A with a relatively low expected payoff and a relatively safe lottery with a relatively high expected payoff. Therefore, in Consideration lottery pairs, leaders and ordinary players do not have an apparent reason to opt for different alternatives if they take into account the expected payoff of the lotteries. Since both lotteries yield the same expected payoff to leaders, they may be indifferent between the two alternatives. By considering ordinary players' preferences, leaders may choose the same option as ordinary players. Similarly to the Determination lottery pairs, in lottery pairs from this block, opposing preferences may arise from the difference in risk coefficients.

Divergence lottery pairs, shown in panel [C] of Table 1, are structured so that the absolute differences in expected values between the two lotteries are equal for the ordinary players and the leader. However, in lottery pairs 11, 12 and 13, ordinary players receive a higher expected payoff if they choose lottery A while lottery B provides a higher expected payoff for the leaders. In addition to the divergent expected payoffs, different risk coefficients in these lotteries may result in opposing preferences between leaders and ordinary players. Lottery pair 10 is a control pair which yields the same expected payoffs for leaders and ordinary players in both lotteries.

Seesaw lottery pairs are presented in panel [D] of Table 1. In every lottery pair from this block, one of the lotteries offers equal expected payoffs as well as individual payoffs with equal 
probability to both leaders and ordinary players. ${ }^{5}$ Since each of these lottery pairs incorporates one lottery that offers equal payoffs to all members of the team and the other lottery that yields different payoffs dependent on players' types, we label these lottery pairs Seesaw lottery pairs.

\subsubsection{INDIVIDUAL TASK}

In the individual task, we elicit individual preferences of experimental participants over all pairs of lotteries shown in Table 1. Since leaders and ordinary players have different payoff schemes, each participant makes choices in each payoff scheme separately (as if she were assigned the type of a leader and the type of the ordinary player). Therefore, in the individual task each participant receives 34 binary lottery choices. Lottery pairs are presented to participants in a random order. ${ }^{6}$

In addition to the 34 binary lottery choices, experimental participants are exposed to the Holt and Laury (2002) risk attitude elicitation procedure (henceforth H\&L procedure). ${ }^{7}$ In this procedure, participants make ten choices between a relatively risky and a relatively safe lottery. The probabilities for the different outcomes of the lotteries are systematically varied from 0.1 to 1. The number of safe choices (i.e., the number of instances a participant opts for a relatively safe lottery) represents a participant's elicited risk attitude rank. This rank can be used as an indicator of risk aversion; i.e., the higher the rank, the more risk averse is an individual. Using the H\&L procedure allows us to reconcile risk attitude information with individual choices and to determine whether individual attitudes towards risk have an impact on the behavior of leaders in the team task.

\subsubsection{TEAM TASK}

The team task consists of 18 stages. The timeline of the team task is provided on Figure 1. In this task, participants are randomly assigned to teams of three. Initially, each player in the team is assigned the type of the ordinary player.

[INSERT Figure 1 HERE]

\footnotetext{
${ }^{5}$ Note that Seesaw lottery pairs are qualitatively different from lottery pair 10 (Block 3), where leaders and ordinary players receive the same expected payoff but different individual payoffs in lotteries A and B.

${ }^{6}$ Pairwise lottery choices from the individual task are provided in the Supplementary Material (Table 10 in Appendix B).

${ }^{7}$ Given that the main experimental task and the risk attitude elicitation procedure are structurally similar, the Holt and Laury (2002) method is the most appropriate technique for our analysis. Holt and Laury (2002) lottery pairs are presented in the Supplementary Material (lottery pairs 18-27 in Table 10 in Appendix B).
} 
At stage $s=0$ at time $t=0$, one of the team members becomes a leader for the whole duration of the team task. Dependent on the way in which a leader is determined, there are two treatments: the $E X$ treatment and the $E N$ treatment.

(1) In the $E X$ treatment, one player in each team is exogenously assigned to be a leader by a random draw.

(2) In the $E N$ treatment, leaders are determined endogenously by a simple majority vote.

In the $E N$ treatment, members of each team are asked to elect a leader. For this purpose, all team members can communicate with each other using an interactive chat. ${ }^{8}$ Any participant may propose him- or herself as a candidate for becoming a team leader. In the $E N$ treatment, every team has three chat periods to discuss the election of the leader and three voting attempts, respectively. Each chat period lasts three minutes, after which all team members submit their anonymous votes. A team member who receives two votes (i.e., a simple majority) becomes a leader. If a simple majority is not reached after the first vote, the team proceeds to the next chat period. Teams who fail to determine the leader endogenously during three voting attempts are assigned an exogenous leader at random. ${ }^{9}$

After all leaders have been determined, teams receive 17 consecutive decision problems at stages $s \in\{1, \ldots, 17\}$. In each problem they choose between paired lotteries. Although these decision problems are identical to the problems used in the individual task, they are shown in a different order and framed differently. ${ }^{10}$

In each decision problem at stages $s \in\{1, \ldots, 17\}$ at time $t=2 s-1$, all three team members, including the leader, are requested to cast an anonymous vote for one of the lotteries in a lottery pair. At time $t=2 s$ the team leader alone is informed about the lottery chosen by a simple majority of the team members. ${ }^{11}$ After that, the leader has an option to either confirm the

\footnotetext{
${ }^{8}$ At the beginning of the team task, participants are assigned identification names Player A, Player B or Player C, which they use in the chat. Targeted chat messages to a particular team member are not possible. Participants are not allowed to reveal their identity (through reporting seat number, name, gender, age, courses taken, etc.) or to use abusive language in the chat. Otherwise, the content of messages within the team is unrestricted.

${ }^{9}$ Before the voting procedure, all participants are informed that the payoff schemes of leaders and ordinary players are different in most cases (without revealing the actual lottery pairs). Please, refer to the experimental instructions in the Supplementary Material (Appendix A) for details.

${ }^{10}$ In the team task each lottery is framed as a "project". Complete list of lottery pairs from the team task as well as their order of appearance is given in the Supplementary Material (Table 11 in Appendix C).

${ }^{11}$ Note that the leader is informed only about the outcome of the majority voting in the team task. Therefore, the leader does not receive information about the voting decision of each team member separately.
} 
team simple majority decision (i.e., to make a democratic decision) or to pick an alternative lottery (i.e., to make an autocratic decision). This decision is final and determines the payoff of the entire team. After all leaders have made their final decisions, these decisions, as well as the team majority voting results, are reported to all team members. Therefore, at the end of each of the stages $s \in\{1, \ldots, 17\}$, ordinary players receive feedback about whether their leader has made an autocratic or a democratic final decision. The realization of the chosen lottery is postponed until the end of the experiment in order to avoid wealth effects.

\subsubsection{OTHER-REGARDING PREFERENCES ELICITATION PROCEDURE}

In addition to the two main experimental tasks, all participants in the experiment are also subjected to the E\&S other-regarding preferences elicitation procedure. For this purpose, all participants are assigned to groups of three. ${ }^{12}$ The E\&S procedure consists of eleven decision situations divided into three clusters: Taxation games, Envy games and Rich and Poor games.

In each situation a monetary amount is allocated among three players: Person 1, Person 2 and Person 3. Each player's payoff is determined based on the choice of Person 2. All participants are asked to make decisions as if they are assigned a role of Person 2. However, the roles are determined only ex post by a random draw. ${ }^{13}$

The E\&S procedure distinguishes between efficiency concerns (henceforth EF), maximin preferences (henceforth MM), and Bolton and Ockenfels (2000) as well as Fehr and Schmidt (1999) models of inequality aversion (henceforth ERC and F\&S, respectively). While Engelmann and Strobel (2004) provide an analysis of their data at the population level as well as at a representative agent level, we extend their approach by classifying participants into cohorts according to their individual other-regarding preferences (EF, ERC, F\&S, and MM). This classification is used in our econometric analysis of the data.

\subsection{EXPERIMENTAL IMPLEMENTATION}

We conducted ten experimental sessions. Eighteen participants took part in each session, yielding a total of 180 participants in the experiment. All participants were undergraduate and graduate students at the University of Innsbruck. Slightly more than one half of them (51.7\%)

\footnotetext{
12 Group composition in the E\&S procedure is different from the team composition in the team task of the experiment.

${ }^{13}$ Engelmann and Strobel (2004) show that the ex post assignment of roles does not have a significant impact on decisions. They run a control treatment where roles are assigned ex ante and receive essentially the same pattern of other-regarding preferences as in a treatment with the ex post assignment of roles.
} 
studied either Economics or Business Administration. The average age of participants was 23 years, and $41.6 \%$ of them were female. The majority of participants $(95.0 \%)$ had some experience with economic experiments but none of them had taken part in a similar experiment before.

We ran four experimental sessions in the $E X$ treatment and six sessions in the $E N$ treatment. To control for order effects between the two main experimental tasks, we constructed two sequences. In Sequence 1, the individual task was followed by the team task. In Sequence 2, the order of main experimental tasks was reversed. The E\&S procedure was always implemented upon completion of the two main experimental tasks. For half of the sessions, participants played Sequence 1 in each treatment, for the other half - Sequence 2. Table 2 provides a summary of treatments and sequences used in the experiment.

\section{[INSERT Table 2 HERE]}

The experiment was computerized using the software z-Tree (Fischbacher, 2007). ${ }^{14}$ Each participant had a visually separated work space. Each work space was equipped with a personal computer, a pen and scratch paper. Built-in digital calculators were available on all computer screens.

Participants received a set of instructions for each task of the experiment separately. Instructions were read aloud and participants had an opportunity to re-read the instructions and ask questions about the procedure in private. To avoid possible framing effects, we used neutral language (i.e., ordinary players were called “players of type 1” and leaders “players of type 2”).

At the end of the experiment participants were asked to fill out a questionnaire which included demographic questions and the Machiavellian scale (henceforth the Mach scale). ${ }^{15}$ The Mach scale is a psychological measure of individual predisposition to guile, deceit and opportunism. The Mach scale, developed by Christie and Gies (1970) and widely used in economics and psychology (e.g., Ahmed and Stewart, 1981; Gunnthorsdottir et al., 2000; and Burks et al., 2003), consists of 20 statements based on Niccolo Machiavelli’s views expressed in his treatises “The Prince” and “Discourses on the First Decade of Titus and Livius”. In the Mach scale task, participants are asked to state their attitude (from strong agreement to strong

\footnotetext{
${ }^{14}$ Program files with experimental treatments are available from the authors upon request.

15 The Supplementary Material (Appendix E) presents the Mach scale questions used in the experiment.
} 
disagreement) toward each of the 20 statements on a seven-point scale. The scores obtained from this scale can be used as a proxy of individual selfishness (Vecchio and Sussmann, 1991). The reason for including the Mach scale in our analysis is to use this proxy as a predictor of a leader's propensity to make autocratic decisions.

To avoid wealth effects, we provided payoff information only at the end of the experiment. One of the binary lottery choices/decision problems/monetary allocation situations was selected from each experimental task at random and participants received the payment according to their decisions. The whole procedure took approximately 1.5 hours. Participants earned, on average, $€ 17.36$, with a median of $€ 16.50$ and a standard deviation of $€ 6.47$. $^{16}$

\subsection{THEORETICAL HYPOTHESES}

One of the main advantages of our experimental design is the simplicity of the theoretical prediction. In the individual task, all participants should reveal their true preferences over a menu of presented lotteries. Furthermore, leaders should make the same choices in both the individual task and the team task of the experiment when they make their final decision. Hence, the individual preferences over binary lottery choices from the individual task form our prediction for leaders' final decisions in the team task. Note, however, that leaders have the option to refrain from revealing their true preferences during the team vote. This decision is essentially cheap talk because it has no consequences for the final payoff.

The behavior of ordinary players in the team task, however, might be different from that of the leader. If ordinary players are fully rational and expect that the leader is also fully rational, they know that their votes in the team task will not have any impact on the final decision. In other words, in the final decision, the leader will always choose the lottery according to her preferences without taking into account the preferences of the other members of the team. Therefore, any voting profile obtained during the team vote constitutes an equilibrium.

However, if ordinary players believe that there is a slight chance that the team leader will make a democratic decision by confirming the majority choice (e.g., if the leader has a preference for accommodating the decisions of the other team members), they have an incentive to reveal their true preferences over the lotteries in the team task. In this case, ordinary players should make the same choices both in the individual task and the team task of the experiment.

\footnotetext{
${ }^{16}$ At the time of the experiment, the exchange rate was $€ 1=\$ 1.56$.
} 
Notice that if the leader confirms the decision made by the simple majority of the team, it does not necessarily imply that she is influenced by the information about the outcome of the voting. Particularly, the leader's vote is in line with the simple majority decision or if the team votes for the same lottery that the leader has chosen in the individual task, then it would appear that she simply behaves according to her individual preferences.

In the team task, we expect that leaders will adopt situational leadership. A leader will make a democratic decision when a leader and ordinary players in a team have the same preferences over lotteries in a lottery pair and an autocratic decision when a leader and ordinary players have opposing preferences. Such agreement or disagreement between leaders and ordinary players may emerge in two different situations. First, ordinary players may vote for a different lottery than the leader during the team task of the experiment. Second, the vote of the ordinary team players in the team task may contradict the leader's individual preferences (i.e., her choice in the individual task). ${ }^{17}$ Our empirical analysis accounts for all these possibilities.

\section{Results}

The resulting data set consists of decisions made by 24 and 36 leaders as well as 48 and 72 ordinary players in the $E X$ and the $E N$ treatment respectively. In the $E N$ treatment, 25 teams (69.4\%) have elected a leader during the first voting attempt, five teams (13.8\%) - during the second attempt, and one team (2.7\%) - during the third attempt. Five teams (13.8\%) have failed to elect a leader. Therefore, in these teams the leader has been assigned exogenously.

We present the results in three subsections. First, we analyze relative frequencies of making autocratic and democratic decisions as well as motives that precipitate these decisions. Second, we examine differences in other-regarding preferences, consistency rates across experimental tasks and risk attitudes between leaders and ordinary players in both treatments. Third, we conduct an econometric analysis that accounts for individual unobserved heterogeneity of leaders in order to detect factors that influence the choice of leadership styles.

\subsection{AUTOCRATIC VERSUS DEMOCRATIC LEADERSHIP}

\subsubsection{DECISIONS}

During the team vote, leaders vote for a different alternative than both of the ordinary players in their team in 441 cases (43.2\%) and for the same alternative as at least one ordinary

\footnotetext{
${ }^{17}$ Obviously, these two situations do not exclude each other.
} 
player in their team in 579 cases (56.8\%). However, leaders make autocratic final decisions in 370 cases (36.3\%) and democratic decisions in 650 cases (63.7\%). Therefore, in 6.9\% of cases, leaders make democratic decisions even though they have voted for a different lottery than the rest of the team.

Leaders make autocratic decisions in 154 cases (37.7\%) in the $E X$ treatment and in 216 cases (35.3\%) in the $E N$ treatment. According to a two-sample Wilcoxon-Mann-Whitney test, the treatment difference is not statistically significant $(p=0.4253)$. Furthermore, elected leaders in the $E N$ treatment, exogenously assigned leaders in the $E X$ treatment and exogenously assigned leaders in the $E N$ treatment make autocratic decisions in $34.2 \%, 37.7 \%$ and $42.4 \%$ of cases, correspondingly. According to the results of a set of Fisher exact tests, the differences between the shares of autocratic decisions among these three clusters of leaders are not statistically significant. ${ }^{18}$ Hence, on the aggregate level, elected and assigned leaders appear to be equally likely to exercise both autocratic and democratic leadership styles. ${ }^{19}$

In order to compare the ex post profitability of autocratic and democratic decisions, we analyze the ex post payoffs in the team task of the experiment. Table 3 provides average and median payoffs received by teams, leaders and ordinary players in the experiment. The payoff of the participants depends not only on their decisions, but also on the realization of random events. Therefore, apart from the actual payoff, Table 3 also includes an alternative payoff that would have resulted if the lottery outcome had been different.

\section{[INSERT Table 3 HERE]}

According to Table 3, democratic decisions appear to be slightly more profitable for the team as a whole than autocratic decisions. This result is weakly significant for the alternative payoff. ${ }^{20}$ Within the team, ordinary players benefit significantly from democratic decisions. They receive, on average, about $€ 1$ more when leaders make democratic decisions compared with autocratic decisions. Ordinary players would also have received significantly higher payoffs from democratic decisions in the alternative outcome. Therefore, it appears that ordinary players

\footnotetext{
${ }^{18}$ All probabilities are greater than 0.3 . The same result is obtained from a set of the Wilcoxon-Mann-Whitney twosample comparisons (all probabilities are greater than 0.25 ).

${ }^{19}$ Leaders make slightly more autocratic decisions in Sequence 1 (38.6\% of cases) than in Sequence 2 (33.9\% of cases), yet the difference is not significant (Wilcoxon-Mann-Whitney test, $p=0.1182$ ).

${ }^{20}$ Detailed results of the Wilcoxon-Mann-Whitney test are reported in Table 3.
} 
benefit from democratic decisions. However, there is no significant difference in the leaders' actual and alternative payoffs from autocratic and democratic decisions.

The data in Table 3 also suggest that when leaders make democratic decisions, they receive essentially the same payoff as ordinary players (Wilcoxon signed-rank test, $p=0.8983$ ). When leaders make autocratic decisions, they receive, on average, almost $€ 2.00$ more than ordinary players $(p=0.0215)$. Therefore, leaders appear to exploit their decision making power by making autocratic decisions in order to earn higher profits.

Figure 2 summarizes the frequencies of autocratic and democratic decisions across all 17 experimental lottery pairs as well as across blocks of lottery pairs. Autocratic decisions exceed $10 \%$ of cases in all lottery pairs but remain below $50 \%$ of cases in most of the lotteries (ID 1 through ID 12 on Figure 2).

\section{[INSERT Figure 2 HERE]}

According to Figure 2, leaders make the lowest number of autocratic decisions in Block 2 (16.1\% of decisions) and the highest in Block 4 (66.3\% of decisions). There is no statistically significant differences in proportions of autocratic and democratic decisions between Block 1 and Block 2 (Fisher exact test, $p=0.1175$ ) and between Block 1 and Block 3 ( $p=0.1686$ ). However, proportions are different between Block 2 and Block $3(p=0.0020)$. Moreover, leaders make autocratic decisions significantly more often in Block 4 than in any other block. ${ }^{21}$

There is considerable individual heterogeneity in leaders' propensity to make autocratic and democratic decisions. Figure 3 plots the number of autocratic decisions per leader versus the number of leaders. Only one leader out of 60 has always made democratic decisions and never resorted to autocratic decisions. All other leaders (98.3\%) have made at least one autocratic decision. The highest number of autocratic decisions was 12 out of 17 . This suggests that individual profiles of leaders are consistent with situational leadership, i.e., leaders use both autocratic and democratic decisions during the experiment. However, the majority of leaders made more democratic decisions than autocratic decisions. Subsection 3.1.2 extends these findings by taking into account leaders’ preferences.

[INSERT Figure 3 HERE]

\footnotetext{
${ }^{21}$ All probabilities of pairwise comparisons according to a set of Fisher's exact tests are lower than 0.0001 .
} 


\subsubsection{Motives}

In order to distinguish among different motives behind autocratic and democratic decisions, the decisions within each of these two categories are partitioned into two subcategories. We distinguish between dissent decisions and power decisions within the category of autocratic decisions. Dissent decisions refer to situations when the leader votes for a different option than ordinary team members during the team vote (i.e., the leader's vote is at odds with the majority vote of the team) and, as a result, makes a final decision contrary to the team. Power decisions describe cases when the leader votes for the same option as the rest of the team, however, after observing the result of the majority vote, changes her mind and opts for a different alternative. ${ }^{22}$

Within democratic decisions, we identify consensus decisions and conformist decisions. Consensus decisions depict situations when the leader and ordinary players vote for the same option during the team vote (i.e., leader's vote coincides with the majority vote) and the leader confirms the team majority vote in the final decision. Conformist decisions identify cases when the leader's vote contradicts the team majority vote; however, after observing the results of the team vote, the leader confirms the team majority decision.

Table 4 provides the absolute and relative frequencies of autocratic and democratic decisions partitioned into four categories: power, dissent, consensus and conformist decisions respectively. According to Table 4, a slight majority of decisions (53.5\%) are consensus decisions. In 33.0\% of cases, leaders make dissent decisions. Conformist decisions are observed in $10.2 \%$ of cases, and leaders make power decisions in $3.2 \%$ of cases.

\section{[INSERT Table 4 HERE]}

While the reasoning behind dissent and consensus decisions is clear and consistent with our theoretical hypotheses in Subsection 2.3, we are particularly interested in the characteristics and determinants of power and conformist decisions. By conducting a cross- and within-treatment non-parametric analysis of power and consensus decisions, we find that leaders are significantly more likely to make power decisions in the $E X$ treatment (5.1\%) than in the $E N$ treatment (2.0\%) (Wilcoxon-Mann-Whitney test, $p=0.0059$ ). This result suggests that exogenously assigned

\footnotetext{
${ }^{22}$ While power decisions may seem irrational, this is not necessarily the case because in our experimental setting leaders may regard their vote during the team vote in the team task as cheap talk and therefore, may randomize between two available alternatives (see Subsection 2.3). Hence, by making power decisions leaders do not necessarily contradict their previous choices.
} 
leaders are more likely than elected leaders to change their mind after they have voted with the rest of the team for the same plan of action. Leaders are also more likely to make conformist decisions in the $E N$ treatment (11.8\%) than in the $E X$ treatment $(7.8 \%)(p=0.0427)$. These results indicate that the way in which leaders are appointed has a strong influence on their propensity to take the preferences of the other team members into account.

\subsection{Characteristics OF LEADERS AND ORDinARy Players}

Before proceeding to the econometric estimation in Subsection 3.3, we classify leaders with respect to their other-regarding preferences, their consistency in making repeated choices and their risk attitudes. These classifications will be useful in estimating the determinants of autocratic versus democratic decisions in Subsection 3.3. We can also employ these classifications to show that the characteristics of leaders are not significantly different across treatments and that ordinary players and leaders have similar characteristics.

\subsubsection{OTHER-REGARDING PREFERENCES}

We use two measures of other-regarding preferences: the E\&S procedure and the Mach scale.

\section{- E\&S PROCEDURE}

In the additional experimental task (see Subsection 2.1.4), all participants take part in the E\&S procedure. ${ }^{23}$ Using the results of the E\&S procedure, we construct a measure of individual other-regarding preferences by using "preference-identifiers" in the Engelmann and Strobel (2004) design. ${ }^{24}$ A "preference-identifier" refers to a decision situation where one of the four other-regarding preference concerns (EF, ERC, F\&S or MM) predicts a different monetary allocation than any other concern (i.e., where one of the concerns is clearly identifiable and distinguishable). ${ }^{25}$

\footnotetext{
${ }^{23}$ At the population/representative agent level, our results are consistent with the findings of Engelmann and Strobel (2004). These results, along with a brief discussion, are provided in the Supplementary Material (Appendix D).

${ }_{24}$ All decision situations, along with the respective EF, ERC, F\&S and MM predictions, are provided in the Supplementary Material (Table 12 in Appendix D).

${ }^{25}$ For example, according to Table 12 (Appendix D in the Supplementary Material) a participant's behavior is consistent with EF and inconsistent with ERC, F\&S and MM if she opts for allocation A in situation Ey in Rich and Poor games. A participant's behavior is consistent with ERC and inconsistent with any other concern if she chooses allocation $\mathrm{C}$ in situations $\mathrm{F}$ and Fx in Taxation games and allocation B in any of the four Envy games. A participant's behavior is consistent with F\&S and inconsistent with any other concern if she selects allocation C in situations $\mathrm{N}$ and $\mathrm{Nx}$ in Envy games. A participant's behavior is consistent with MM and not with any other concern if she opts for allocation B in situation P in Rich and Poor games.
} 
Using "preference-identifiers", participants are divided into six cohorts: EF, ERC, F\&S, MM, Combination and None. An individual is assigned to either the EF, ERC, F\&S or MM cohort if she made at least one choice consistent with EF, ERC, F\&S or MM correspondingly. An individual is assigned to the Combination cohort if she made choices consistent with several other-regarding preference concerns in the respective "preference-identifiers" ${ }^{26}$ If a participant has not made choices consistent with any of the available other-regarding preference concerns in the distinguishing situations, she is assigned to the None cohort. Results of this individual measure are reported in Table 5.

\section{[INSERT Table 5 HERE]}

According to our individual measure, more than half of the experimental participants (52.8\%) make decisions consistent with only one other-regarding preference concern. 33.9\% of participants are classified as efficiency-oriented. They are assigned to the EF cohort. At the same time, $11.7 \%$ of participants appear to maximize the minimum payoff. They are assigned to the MM cohort. The share of participants classified as inequality averse, whose decisions are consistent with either ERC (6.1\%) or F\&S (1.1\%), is relatively small. ${ }^{27}$ Looking at differences between leaders and ordinary players a Fisher exact test suggests that leaders and ordinary players are not statistically significantly different in their propensities to exhibit behavior consistent with $\mathrm{EF}(p=0.3470)$, ERC $(p=0.0690), \mathrm{F} \& \mathrm{~S}(p=0.5570)$ or $\mathrm{MM}(p=0.1060)$ concerns.

\section{- Mach ScAle}

In addition to the $\mathrm{E} \& \mathrm{~S}$ procedure, we use the Mach scale in order to determine whether leaders who report high levels of selfishness are more likely to make autocratic decisions than leaders who report high levels of altruism. Based on the Mach scale scores, we construct a relative ranking of leaders from 1 ("very selfish") to 7 ("very altruistic"). The ranks are assigned in descending order such that leaders with the highest Mach scores receive the highest rank (rank 1) and leaders with the lowest score receive the lowest rank (rank 7). We incorporate this ranking in our econometric analysis.

\footnotetext{
${ }^{26}$ For example, if a participant choses allocation A in situation Ey and allocation C in situation F (see Table 12 in Appendix D of the Supplementary Material), she is assigned to the Combination cohort.

${ }^{27}$ Note that this result does not necessarily suggest that the data provide little support for the models of Bolton and Ockenfels (2000) and Fehr and Schmidt (1999) because participants in the Combination cohort often make decisions consistent with ERC or F\&S along with other concerns.
} 
The data suggest that there are no significant differences in the Mach scores between ordinary players and leaders (Wilcoxon-Mann-Whitney test, $p=0.2281$ ). Scores range between 65 and 138 (with the median of 93) for ordinary players and between 67 and 130 (with the median of 96) for leaders. Leaders in the $E X$ and the $E N$ treatment are very similar in their Mach scores (Wilcoxon-Mann-Whitney test, $p=0.6183$ ). Furthermore, there are no statistically significant differences in Mach scores between elected leaders in the EN treatment and assigned leaders in both treatments (Wilcoxon-Mann-Whitney test, $p=0.5292$ ).

\subsubsection{CONSISTENCY OF DECISIONS BETWEEN INDIVIDUAL AND TEAM TASKS}

Recall from our experimental design (see Section 2.1) that leaders make decisions about their preferred lottery in each lottery pair at three different points in time during the experiment: (a) in the individual task; (b) during the team vote in the team task; and (c) when making their final decisions after observing the outcome of the team majority vote. Ordinary players make decisions over the same lottery pairs in the individual task and during the team vote in the team task. Repeated decisions on the same lottery pairs allow examining an individual's degree of inconsistency across experimental tasks.

\section{[INSERT Table 6 HERE]}

Variable IND-TM in Table 6 shows the percentage of inconsistent decisions between the individual task and the team vote in all lottery pairs both for ordinary players and leaders. Variables TM-FIN (team vote versus final decision), IND-FIN (individual task versus final decision) and THR (inconsistency throughout the experiment ${ }^{28}$ ) are constructed only for leaders.

The data suggest that leaders and ordinary players are very similar when they are compared according to the inconsistency criterion. Leaders and ordinary players make inconsistent decisions between the individual task and the team vote in $26.5 \%$ and $25.7 \%$ of cases (Fisher exact test, $p=0.9999$ ) respectively. Since leaders may not always reveal their true preferences during the team vote, we also consider the percentage of inconsistent decisions between the individual task and leaders' final decisions (31.1\%). The comparison between IND-FIN for leaders and IND-TM for ordinary players does not reveal statistically significant differences $(p=$

\footnotetext{
${ }^{28}$ THR is the strongest measure of consistency for leaders. According to this measure, a decision is considered consistent only if a leader has repeatedly chosen the same alternative in a given lottery pair throughout the experiment, i.e., in the individual task, in the team vote and in the final decision. Otherwise, a decision is considered to be inconsistent according to THR. Note that IND-TM measure for ordinary players is equivalent to THR measure for ordinary players.
} 
0.4302); neither does the comparison between THR for leaders and IND-TM for ordinary players $(p=0.1637) .{ }^{29}$ Note that the low inconsistency rates between the team vote and the final decisions (see Table 6) suggest that leaders appear to vote for their preferred lottery rather than randomize between the two alternatives during the team vote.

\subsubsection{Risk ATtitudes}

Recall from the experimental design (see Subsection 2.1.2) that we elicit participants' attitudes towards risk by using the H\&L procedure. ${ }^{30}$ According to the procedure, the majority of experimental participants (65.5\%) are at least slightly risk averse, $18.3 \%$ are risk neutral and $5.6 \%$ are risk seeking. The ranks of 19 (10.6\%) participants are excluded from consideration because they have switched between a relatively safe and a relatively risky lottery more than once. The average risk attitude rank of the remaining participants is 5.65 with a median of 6.00 and a standard deviation of 1.75. Leaders and ordinary players have essentially the same risk attitudes according to both a within-treatment and a cross-treatment non-parametric comparison. ${ }^{31}$

\subsection{DETERMINANTS OF LEADERS’ DECISIONS}

In this subsection we identify factors that influence the decisions of leaders to make autocratic and democratic decisions. Since the decision variable is binary and the analysis in the previous sections indicates that leaders are heterogeneous in their propensity to adopt either of the two leadership styles, we use a random intercept logit regression (e.g., Longford, 1994). Each leader $i \in[1, N]$ is faced with two choices after observing the result of the team vote on each lottery pair $l \in[1, L]$. The dependent variable is a dummy variable $y_{i}^{l}$, specified as follows:

$$
y_{i}^{l}=\left\{\begin{array}{l}
1, \text { if the leader makes an autocratic decision } \\
0, \text { if the leader makes a democratic decision }
\end{array}\right.
$$

The probability that that leader $i$ opts for an autocratic decision in lottery pair $l$ is given by:

\footnotetext{
${ }^{29}$ The overall inconsistency rates in our experiment are very similar to the $25.0 \%$ inconsistency rate reported in the previous experiments on repeated choice in individual decision making under risk (e.g., Hey and Orme, 1994).

${ }^{30}$ Results of the H\&L procedure along with the relevant non-parametric statistics are presented in the Supplementary Material (Table 13 in Appendix F).

${ }^{31}$ In addition to the incentivized H\&L procedure, we also administer a non-incentivized risk attitude measure. In the post-experimental questionnaire, participants are asked to indicate their attitudes toward risk on a scale from 1 (very risk seeking) to 7 (very risk averse). Answers of the participants form the self-reported risk attitude rank. This rank is used in the econometric analysis together with the elicited risk attitude rank.
} 


$$
P\left(y_{i}^{l}=1\right)=\frac{\exp \left(\beta_{1} X 1_{i}^{l}+\beta_{2} X 2_{i}^{l}+\cdots+\beta_{M} X M_{i}^{l}+u_{i}\right)}{1+\exp \left(\beta_{1} X 1_{i}^{l}+\beta_{2} X 2_{i}^{l}+\cdots+\beta_{M} X M_{i}^{l}+u_{i}\right)}
$$

where $X 1_{i}^{l} \ldots X M_{i}^{l}$ are explanatory variables, described in Table $7 ; \beta_{1} \ldots \beta_{M}$ are regression coefficients and $u_{i}$ is a vector, capturing unobserved individual heterogeneity of leaders.

\section{[INSERT Table 7 HERE]}

We assume that the unobserved heterogeneity $u$ is identically and independently distributed over individual leaders and follows a multivariate normal distribution with mean $u$ and variancecovariance matrix $W, u \sim f(u, W)$. The conditional log-likelihood function of the random intercept logit regression has the following form:

$$
L L=\prod_{i=1}^{N} \int_{-\infty}^{+\infty} \prod_{l=1}^{L}\left(\frac{\exp \left(\beta_{1} X 1_{i}^{l}+\beta_{2} X 2_{i}^{l}+\cdots+\beta_{M} X M_{i}^{l}+u_{i}\right)}{1+\exp \left(\beta_{1} X 1_{i}^{l}+\beta_{2} X 2_{i}^{l}+\cdots+\beta_{M} X M_{i}^{l}+u_{i}\right)}\right) f(u) d u
$$

To insure the robustness of the estimation results, the log-likelihood function is approximated using the adaptive quadrature method (Rabe-Hesketh et al., 2002). ${ }^{32}$ We conduct estimations of four two-level models with different number of explanatory variables and unobserved heterogeneity at the level of individual leaders. We also estimate a three-level model where we add a random intercept at the level of efficiency concerns. ${ }^{33}$ Table 8 summarizes the results of the random intercept logit estimation.

\section{[INSERT Table 8 HERE]}

We find that seven factors influence leaders’ propensity to make autocratic and democratic decisions. Opposing preferences have a significant impact. Particularly, leaders are more likely to make autocratic decisions if the result of the team majority voting contradicts with the leader's vote during the team task (OPPREF1) or the choice of the leader in the individual task (OPPREF2). Leaders whose final decisions in the team task are consistent with their choices in the individual task are also more likely to make autocratic decisions (CONS1).

\footnotetext{
${ }^{32}$ Adaptive quadrature refers to a Bayesian method which enhances standard Gauss-Hermite quadrature by taking into account the posterior distribution of the unobserved heterogeneity. The estimation has been conducted using the GLLAMM plug-in for the Stata 10.0 package. The programming code along with the data is available from the authors upon request.

${ }^{33}$ We have also conducted estimations with random intercept at the level of lottery pair blocks. However, our results have suggested that unobserved heterogeneity at the block level was not an important determinant of the leadership style choice.
} 
Leaders who care about efficiency $(\boldsymbol{E F})$ according to the individual measure of otherregarding preferences based on the E\&S procedure are more likely to make autocratic decisions. Interestingly, non-parametric comparisons from the previous sections do not reveal statistically significant differences between two treatments. However, when we account for the unobserved heterogeneity, leaders in the $E X$ treatment appear to be more likely to opt for autocratic decisions than leaders in the EN treatment (TREATMENT). It is important to note that leaders in the $E X$ treatment and the EN treatment differ neither in their elicited risk attitude ranks nor in their other-regarding preferences. Hence, this treatment effect appears to result from the leaders’ assignment procedure itself.

We observe a gender effect: female leaders are more likely to make autocratic decisions than male leaders (GENDER). We also find that the relative rank of leaders according to the Machiavellian scale is statistically significant (MACH). Relatively more selfish leaders are more likely to make autocratic decisions. ${ }^{34}$ Interestingly, neither of the two risk attitude measures (ERAR and SRAR) have a significant impact on leaders' decisions. It is also noteworthy that neither inequity aversion nor maximin preferences influence the likelihood of autocratic decisions.

In the estimated two-level models (see Table 8), the standard deviation of the unobserved individual heterogeneity of leaders ranges between 0.1641 and 0.7428 . In the three-level model, the standard deviation of the unobserved individual heterogeneity is equal to 0.2531 and the standard deviation of the unobserved heterogeneity in efficiency preferences is equal to 0.3067 . This indicates that individual unobserved heterogeneity of leaders, as well as individual heterogeneity in leaders’ other-regarding preferences for efficiency, has an important impact on leaders’ decisions.

In addition to identifying the determinants of leaders' decisions to adopt either an autocratic or a democratic leadership style, we explore factors that influence their choices associated with a particular motive (i.e., dissent, conformist, consensus, and power decisions) using a random intercept multinomial logit estimation (e.g., Haan and Uhlendorff, 2006). The probability that leader $i(i \in[1, N])$ chooses action $j(j \in[0,3]$ where $0=$ consensus decision; $1=$ dissent

\footnotetext{
${ }^{34}$ According to the three-level model female leaders and leaders with high Mach scores are more likely to make autocratic decisions. However, in the three-level model these results are only marginally significant $(p=0.0560$ and $p=0.0640$, respectively).
} 
decision; $2=$ conformist decision; and $3=$ power decision in lottery pair $l(l \in[1, L])$ is given by

$$
P\left(j \mid M 1_{i}^{l} \ldots M N_{i}^{l}, \alpha_{i}\right)=\frac{\exp \left(M 1_{i}^{l} \beta_{1 j}+M 2_{i}^{l} \beta_{2 j}+\cdots+M N_{i}^{l} \beta_{N j}+\alpha_{i j}\right)}{\sum_{k=0}^{3} \exp \left(M 1_{i}^{l} \beta_{1 k}+M 2_{i}^{l} \beta_{2 k}+\cdots+M N_{i}^{l} \beta_{N k}+\alpha_{i k}\right)}
$$

where $M 1_{i}^{l}, \ldots, M N_{i}^{l}$ are observed explanatory variables listed in the first column of Table 9 (with the corresponding descriptions in Table 7), ${ }^{35} \alpha_{i j}$ are unobserved individual effects and $\beta_{1 j}, \ldots, \beta_{N j}$ are regression coefficients. The log-likelihood function of the multinomial logit with random intercepts has the following form:

$$
L L=\prod_{i=1}^{N} \int_{-\infty}^{+\infty} \prod_{l=1}^{L} \prod_{j=0}^{3}\left(\frac{\exp \left(M 1_{i}^{l} \beta_{1 j}+M 2_{i}^{l} \beta_{2 j}+\cdots+M N_{i}^{l} \beta_{N j}+\alpha_{j}\right)}{\sum_{k=0}^{3} \exp \left(M 1_{i}^{l} \beta_{1 k}+M 2_{i}^{l} \beta_{2 k}+\cdots+M N_{i}^{l} \beta_{N k}+\alpha_{k}\right)}\right)^{d_{i j l}} f(\alpha) d \alpha
$$

where $d_{i j l}=1$ if individual $i$ chooses alternative $j$ in the lottery pair $l$ and $d_{i j l}=0$ otherwise. Action $0=$ consensus decision is taken as a base category for the model estimation. ${ }^{36}$ Unobserved heterogeneity $\alpha_{i j}$ is assumed to be independent of the explanatory variables. The integral in the log-likelihood function (5) is approximated using the adaptive quadrature method.

\section{[INSERT Table 9 HERE]}

In the random intercept multinomial logit analysis we estimate models with heterogeneity on several different levels: in the two-level model, we use a random intercept at the level of individual leaders; in the three-level model - at the level of individual leaders and leaders' efficiency concerns as well as at the level of lottery pair blocks. Results of the estimation are presented in Table 9.

We find that leaders who care about efficiency $(\boldsymbol{E F})$ are more likely to make dissent decisions than consensus decisions. Participants who are elected to be leaders on later voting attempts (VATTEMPT) during the preliminary stage $s=0$ in the team task of the $E N$ treatment (see Figure 1) have a higher propensity to make dissent decisions than consensus decisions. Dissent decisions are also more likely to be observed in the $E X$ treatment than in the $E N$

\footnotetext{
${ }^{35}$ We dropped several variables from Table 7 in order to conduct the random intercept multinomial logit estimation. For example, variables, such as opposing preferences dummies, are deleted because they are used in the construction of the dependent variable for the multinomial logit estimation. Other variables (e.g., ERC and F\&S dummies) are eliminated due to the lack of variability. Several variables have also been dropped in the process of estimation due to low predictive power.

${ }^{36}$ We have also conducted estimations with dissent, conformist and power decisions as base categories. The results are robust and do not depend the choice of the base variable.
} 
treatment (TREATMENT). The two-level model also reveals that leaders with economics or business administration background are more likely to resort to dissent decisions (MAJOR).

Our results also suggest that leaders who indicate having acquaintances in the same experimental session (ACQUAINTANCES) are more likely to make conformist decisions. ${ }^{37}$ Power decisions are influenced by the sequence (variable SEQUENCE) as well as the emotional state of the leader (variable MOOD1). Leaders who play Sequence 1 and leaders who are in a bad mood on the day of the experiment are more likely to make power decisions. ${ }^{38}$

We also find that leaders who tend to exhibit high rates of overconfidence in their field of study/work (OVERCONF2) are more likely to make dissent, conformist and power decisions than consensus decisions. Finally, unobserved heterogeneity at the level of individual leaders, their efficiency concerns as well as lottery pair blocks influence leader's propensity to make dissent, conformist and power decisions.

\section{ConCLUSION}

In this paper we propose a new framework for research on leadership styles. Our approach takes into account the formal authority of leaders in hierarchical organizations as well as leaders' flexibility to choose and switch between two styles: an autocratic leadership style and a democratic leadership style. Within this framework, we pay particular attention to the impact of other-regarding preferences on the choice of leadership style.

Our approach relates the growing economics literature on leadership with research on otherregarding preferences. This has several important practical implications for organizations design. Particularly, our results suggest that organizations with preferences for a particular leadership style need to look for leaders (e.g., CEOs, upper- and middle-level managers) with specific other-regarding preferences.

\footnotetext{
${ }^{37}$ Participants can see each other when they enter the experimental laboratory. In our sample, 41 leaders (68.3\%) reported that they did not have any acquaintances in the same experimental session; 12 leaders $(20.0 \%)$ indicated that they knew one person in their session and 7 leaders (11.7\%) reported that they knew two people in their session. Recall from the experimental design (Subsection 2.1) that 18 participants take part in each session and that the assignment to a team is random. Hence, the likelihood of playing in a team with an acquaintance is very low.

${ }^{38}$ The tree-level model with random intercepts at the level of individual leaders and their EF concerns reveals that more risk averse leaders are more likely to make power decisions. This may suggest that highly risk averse leaders are more likely to be unsure about their decisions, which results in them changing their mind even if they have agreed with the rest of their team during the team vote.
} 
We find that the majority of leaders adopt situational leadership by making both autocratic and democratic decisions. The manner in which the leader is determined appears to be important. Elected leaders are more likely to make conformist decisions than exogenously assigned leaders. This suggests that an elected leader has a significantly higher probability than an assigned leader of accommodating preferences of the other team members even if these preferences are at odds with leader's point of view. Therefore, elected leaders are more likely to seek consensus within the team by compromising. At the same time, exogenously assigned leaders appear to be less interested in reaching the team consensus than elected leaders and tend to overrule team majority opinion even after having reached an agreement with the other team members.

Both leadership styles have their advantages and disadvantages for the organization as a whole. On the one hand, democratic decisions may benefit the work morale of team members and have a positive effect on the climate within a hierarchical organization. On the other hand, democratic decisions may result in ignoring more efficient but less socially accepted options and have a negative influence on team results (e.g., Davis, 1992). Autocratic decisions may undermine work morale. Nevertheless, by making unpopular decisions, leaders might be able to reach team goals in the most efficient way which benefits both leaders themselves as well as their subordinates.

In our experiment, we find that autocratic and democratic decisions appear to be equally profitable for teams as a whole. However, while leaders receive essentially the same payoff from autocratic and democratic decisions, ordinary players earn significantly more money from democratic rather than from autocratic decisions.

By investigating the link between other-regarding preferences and leadership styles, we find that leaders are more likely to make autocratic decisions if they have a preference for efficiency (which has been found to be an important motivational factor in the experiments of, e.g., Charness and Rabin, 2002). This result confirms the view that autocratic leaders are more resultor goal-oriented than democratic leaders (e.g., Rotemberg and Saloner, 1993). It also shows that there is a correlation between other-regarding preferences elicited through the procedure of Engelmann and Strobel (2004) which uses simple and risk-free distribution choices and decision making under risk. Our results show that a simple measure of other-regarding preferences can be a useful predictor for behavior outside the domain of pure, non-stochastic allocation tasks. We 
have also found that leaders who report high levels of selfishness are more likely to make autocratic decisions. However, our data do not provide compelling evidence that inequity aversion is an important motive in the decision making of leaders.

Interestingly, women have a higher propensity to make autocratic decisions than men. It is difficult to speculate about the underlying reasons for this result. One of the possible explanations is that female team leaders apply more aggressive strategies than their male counterparts. This phenomenon is often confirmed by the empirical observation that there are few women in top leadership/managerial positions. Therefore, women have to exert more effort and act in tougher ways in order to compete with men. Another interesting result is that apart from measurable factors and demographic characteristics, unobserved heterogeneity of leaders has an important impact on their choices.

Finally, an important finding is that leaders who are trying to maintain consistency between their individual preferences in the individual choice task and their opinion in the team decision making task are more likely to be autocratic. This result relates to the emerging literature which explores the effects of group membership on individual behavior (e.g., Charness et al., 2007; Chen and Li, forthcoming). Particularly, this finding implies that participants who are least likely to change their individual preferences, due to becoming a member of a team, are more likely to exhibit a particular (autocratic) leadership style. The choice of leadership style appears to be affected by the degree to which the individual behavior of leaders is influenced by the group membership. In other words, a social context (e.g., group membership) has a significant impact on leaders' decision making. This finding provides an additional support to our conjecture that other-regarding preferences are important determinants of leadership styles. 
TABLES AND Figures

Table 1 [A] Determination Lottery Pairs*

\begin{tabular}{|c|c|c|c|c|c|c|c|c|c|c|c|c|c|}
\hline $\begin{array}{l}\text { Lottery } \\
\text { pair ID }\end{array}$ & $\begin{array}{l}\text { Lottery } \\
\text { ID }\end{array}$ & $\begin{array}{l}\text { Team } \\
\text { payoff }\end{array}$ & $\begin{array}{c}\text { Ordinary } \\
\text { player's } \\
\text { payoff }\end{array}$ & $\begin{array}{l}\text { Leader's } \\
\text { payoff }\end{array}$ & $\begin{array}{l}\text { Proba- } \\
\text { bility }\end{array}$ & $\begin{array}{l}\text { Expected } \\
\text { payoff of } \\
\text { the } \\
\text { lottery } \\
\text { for } \\
\text { ordinary } \\
\text { player }\end{array}$ & $\begin{array}{c}\text { Expected } \\
\text { payoff } \\
\text { of } \\
\text { the } \\
\text { lottery } \\
\text { for } \\
\text { leader }\end{array}$ & $\begin{array}{c}\text { Absolute } \\
\text { difference } \\
\text { in expected } \\
\text { payoffs } \\
\text { between } \\
\text { two } \\
\text { lotteries for } \\
\text { ordinary } \\
\text { player }\end{array}$ & $\begin{array}{c}\text { Absolute } \\
\text { difference } \\
\text { in } \\
\text { expected } \\
\text { payoffs } \\
\text { between } \\
\text { two } \\
\text { lotteries } \\
\text { for leader }\end{array}$ & $\begin{array}{l}\text { Risk } \\
\text { coeffi- } \\
\text { cient }(\sigma) \\
\text { for } \\
\text { ordinary } \\
\text { player }\end{array}$ & $\begin{array}{c}\text { Risk } \\
\text { coeffi- } \\
\text { cient } \\
(\sigma) \\
\text { for } \\
\text { leader }\end{array}$ & $\begin{array}{l}\text { Brief } \\
\text { descrip- } \\
\text { tion for } \\
\text { ordinary } \\
\text { player }\end{array}$ & $\begin{array}{c}\text { Brief } \\
\text { descrip- } \\
\text { tion } \\
\text { for } \\
\text { leader* }\end{array}$ \\
\hline \multirow{2}{*}{1} & A & $\begin{array}{c}30.3 \\
7.2\end{array}$ & $\begin{array}{l}7.9 \\
3.1\end{array}$ & $\frac{14.5}{1}$ & $\begin{array}{l}1 / 3 \\
2 / 3\end{array}$ & 4.7 & 5.5 & \multirow{2}{*}{0} & \multirow{2}{*}{1} & 2.3 & 6.4 & HR/SP & HR/HP \\
\hline & B & $\begin{array}{c}9.3 \\
16.2 \\
\end{array}$ & $\begin{array}{l}3.9 \\
5.1 \\
\end{array}$ & $\begin{array}{c}1.5 \\
6\end{array}$ & $\begin{array}{l}1 / 3 \\
2 / 3\end{array}$ & 4.7 & 4.5 & & & 0.6 & 2.1 & LR/SP & LR/LP \\
\hline \multirow{3}{*}{2} & A & $\begin{array}{c}38.2 \\
3.1\end{array}$ & $\begin{array}{l}9.7 \\
1.3\end{array}$ & $\begin{array}{c}18.8 \\
0.5\end{array}$ & $\begin{array}{l}1 / 3 \\
2 / 3\end{array}$ & 4.1 & 6.6 & \multirow{3}{*}{0} & \multirow{3}{*}{2} & 4.0 & 8.6 & HR/SP & HR/HP \\
\hline & \multirow{2}{*}{ B } & 9.2 & 3.5 & 2.2 & $1 / 3$ & 41 & 46 & & & 04 & 17 & IR/SP & $\mathrm{I}$ R/I P \\
\hline & & 14.6 & 4.4 & 5.8 & $2 / 3$ & 4.1 & 4.6 & & & 0.4 & $1 .{ }^{1}$ & LK/SP & LK/LP \\
\hline \multirow{3}{*}{3} & A & $\begin{array}{c}39.1 \\
8.8\end{array}$ & $\begin{array}{c}9 \\
3.6\end{array}$ & $\begin{array}{c}21.1 \\
1.6\end{array}$ & $\begin{array}{l}1 / 3 \\
2 / 3\end{array}$ & 5.4 & 8.1 & \multirow{3}{*}{0} & \multirow{3}{*}{3} & 2.6 & 9.2 & HR/SP & HR/HP \\
\hline & \multirow{2}{*}{ B } & 11.5 & 4.8 & 1.9 & $1 / 3$ & & & & & & & & \\
\hline & & 18.1 & 5.7 & 6.7 & $2 / 3$ & 5.4 & 5.1 & & & 0.4 & 2.3 & LR/SP & LR/LP \\
\hline \multirow{4}{*}{4} & \multirow{2}{*}{ A } & 35 & 9 & 17 & $1 / 3$ & 4.3 & 6.3 & \multirow{4}{*}{0} & \multirow{4}{*}{1} & 3.3 & 7.6 & $\mathrm{HR} / \mathrm{SP}$ & HR/HP \\
\hline & & 4.9 & 2 & 0.9 & $2 / 3$ & & & & & & & & \\
\hline & \multirow{2}{*}{ B } & 5.2 & 2 & 1.2 & $1 / 3$ & 43 & 53 & & & 17 & 29 & LR/SP & L R/I P \\
\hline & & 18.3 & 5.5 & 7.3 & $2 / 3$ & 4.3 & 3.3 & & & 1.7 & 2.9 & LK/SP & LK/LF \\
\hline \multirow{4}{*}{5} & \multirow{2}{*}{ A } & 36.4 & 8.7 & 19 & $1 / 3$ & 47 & 72 & \multirow{4}{*}{0} & \multirow{4}{*}{2} & 28 & 83 & $\mathrm{HR} / \mathrm{SP}$ & HR/HP \\
\hline & & 6.7 & 2.7 & 1.3 & $2 / 3$ & & & & & & & & \\
\hline & \multirow{2}{*}{ B } & 9.6 & 3.9 & 1.8 & $1 / 3$ & 47 & 52 & & & 06 & 24 & LR/SP & $\mathrm{I} / \mathrm{P} \mathrm{P}$ \\
\hline & & 17.1 & 5.1 & 6.9 & $2 / 3$ & 4.1 & 5.2 & & & 0.0 & 2.4 & LFV & LK/LF \\
\hline \multirow{4}{*}{6} & \multirow{2}{*}{ A } & 47.1 & 11.7 & 23.7 & $1 / 3$ & 5.1 & 8.5 & \multirow{4}{*}{0} & \multirow{4}{*}{3} & 4.7 & 10.8 & HR/SP & HR/HP \\
\hline & & 4.5 & 1.8 & 0.9 & $2 / 3$ & & & & & & & & \\
\hline & \multirow{2}{*}{ B } & 10.5 & 4.3 & 1.9 & $1 / 3$ & 51 & 5.5 & & & 0.6 & 2.6 & LR/SP & LR/LP \\
\hline & & 18.3 & 5.5 & 7.3 & $2 / 3$ & 0.1 & & & & & & & \\
\hline
\end{tabular}

*Abbreviations: HR- relatively high risk; LR - relatively low risk; HP - relatively high expected payoff; LP - relatively low expected payoff; SP the same expected profit as the alternative lottery. (Experimental participants receive information contained only in columns 3-6). 


\section{Table 1 [B] Consideration Lottery Pairs*}

\begin{tabular}{|c|c|c|c|c|c|c|c|c|c|c|c|c|c|}
\hline $\begin{array}{l}\text { Lottery } \\
\text { pair ID }\end{array}$ & $\begin{array}{l}\text { Lottery } \\
\text { ID }\end{array}$ & $\begin{array}{l}\text { Team } \\
\text { payoff }\end{array}$ & $\begin{array}{c}\text { Ordinary } \\
\text { player's } \\
\text { payoff }\end{array}$ & $\begin{array}{c}\text { Leader's } \\
\text { payoff }\end{array}$ & $\begin{array}{l}\text { Proba- } \\
\text { bility }\end{array}$ & $\begin{array}{l}\text { Expected } \\
\text { payoff of } \\
\text { the } \\
\text { lottery } \\
\text { for } \\
\text { ordinary } \\
\text { player }\end{array}$ & $\begin{array}{l}\text { Expected } \\
\text { payoff } \\
\text { of } \\
\text { the } \\
\text { lottery } \\
\text { for } \\
\text { leader }\end{array}$ & $\begin{array}{c}\text { Absolute } \\
\text { difference } \\
\text { in expected } \\
\text { payoffs } \\
\text { between } \\
\text { two } \\
\text { lotteries for } \\
\text { ordinary } \\
\text { player }\end{array}$ & $\begin{array}{c}\text { Absolute } \\
\text { difference } \\
\text { in } \\
\text { expected } \\
\text { payoffs } \\
\text { between } \\
\text { two } \\
\text { lotteries } \\
\text { for leader }\end{array}$ & $\begin{array}{l}\text { Risk } \\
\text { coeffi- } \\
\text { cient }(\sigma) \\
\text { for } \\
\text { ordinary } \\
\text { player }\end{array}$ & $\begin{array}{c}\text { Risk } \\
\text { coeffi- } \\
\text { cient } \\
(\sigma) \\
\text { for } \\
\text { leader }\end{array}$ & $\begin{array}{l}\text { Brief } \\
\text { descrip- } \\
\text { tion for } \\
\text { ordinary } \\
\text { player }\end{array}$ & $\begin{array}{c}\text { Brief } \\
\text { descrip- } \\
\text { tion } \\
\text { for } \\
\text { leader* }\end{array}$ \\
\hline \multirow{2}{*}{7} & A & $\begin{array}{c}25.7 \\
4.5\end{array}$ & $\begin{array}{c}7.9 \\
2\end{array}$ & $\begin{array}{l}9.9 \\
0.5\end{array}$ & $\begin{array}{l}1 / 3 \\
2 / 3\end{array}$ & 4.0 & 3.6 & \multirow{2}{*}{1} & \multirow{2}{*}{0} & 2.8 & 4.4 & HR/HP & HR/SP \\
\hline & B & $\begin{array}{c}7.7 \\
10.5 \\
\end{array}$ & $\begin{array}{c}2.9 \\
3\end{array}$ & $\begin{array}{l}1.9 \\
4.5\end{array}$ & $\begin{array}{l}1 / 3 \\
2 / 3\end{array}$ & 3.0 & 3.6 & & & 0.1 & 1.2 & LR/LP & LR/SP \\
\hline \multirow[b]{2}{*}{8} & A & $\begin{array}{c}16 \\
8\end{array}$ & $\begin{array}{l}4 \\
3\end{array}$ & $\begin{array}{l}8 \\
2\end{array}$ & $\begin{array}{l}1 / 3 \\
2 / 3\end{array}$ & 3.3 & 4 & \multirow{2}{*}{2} & \multirow{2}{*}{0} & 0.5 & 2.8 & LR/LP & HR/SP \\
\hline & B & $\begin{array}{l}16 \\
14\end{array}$ & $\begin{array}{c}7 \\
4.5\end{array}$ & $\begin{array}{l}2 \\
5\end{array}$ & $\begin{array}{l}1 / 3 \\
2 / 3\end{array}$ & 5.3 & 4 & & & 1.2 & 1.4 & HR/HP & LR/SP \\
\hline \multirow[b]{2}{*}{9} & A & $\begin{array}{l}29 \\
5.2\end{array}$ & $\begin{array}{l}6.6 \\
1.9\end{array}$ & $\begin{array}{c}15.8 \\
1.4 \\
\end{array}$ & $\begin{array}{l}1 / 3 \\
2 / 3\end{array}$ & 3.5 & 6.2 & \multirow{2}{*}{3} & \multirow[b]{2}{*}{0} & 2.2 & 6.8 & HR/LP & HR/SP \\
\hline & B & $\begin{array}{c}23 \\
11.4\end{array}$ & $\begin{array}{l}7.3 \\
4.8\end{array}$ & $\begin{array}{l}8.4 \\
1.8\end{array}$ & $\begin{array}{l}2 / 3 \\
1 / 3\end{array}$ & 6.5 & 6.2 & & & 1.2 & 3.1 & LR/HP & LR/SP \\
\hline
\end{tabular}

*Abbreviations: HR- relatively high risk; LR - relatively low risk; HP - relatively high expected payoff; LP - relatively low expected payoff; SP — the same expected profit as the alternative lottery. (Experimental participants receive information contained only in columns 3-6). 
Table 1 [C] Divergence Lottery Pairs

\begin{tabular}{|c|c|c|c|c|c|c|c|c|c|c|c|c|c|}
\hline $\begin{array}{l}\text { Lottery } \\
\text { pair ID }\end{array}$ & $\begin{array}{c}\text { Lottery } \\
\text { ID }\end{array}$ & $\begin{array}{c}\text { Team } \\
\text { payoff }\end{array}$ & $\begin{array}{c}\text { Ordinary } \\
\text { player's } \\
\text { payoff }\end{array}$ & $\begin{array}{c}\text { Leader's } \\
\text { payoff }\end{array}$ & $\begin{array}{l}\text { Proba- } \\
\text { bility }\end{array}$ & $\begin{array}{l}\text { Expected } \\
\text { payoff of } \\
\text { the } \\
\text { lottery } \\
\text { for } \\
\text { ordinary } \\
\text { player }\end{array}$ & $\begin{array}{l}\text { Expected } \\
\text { payoff } \\
\text { of } \\
\text { the } \\
\text { lottery } \\
\text { for } \\
\text { leader }\end{array}$ & $\begin{array}{c}\text { Absolute } \\
\text { difference } \\
\text { in expected } \\
\text { payoffs } \\
\text { between } \\
\text { two } \\
\text { lotteries for } \\
\text { ordinary } \\
\text { player }\end{array}$ & $\begin{array}{c}\text { Absolute } \\
\text { difference } \\
\text { in } \\
\text { expected } \\
\text { payoffs } \\
\text { between } \\
\text { two } \\
\text { lotteries } \\
\text { for leader }\end{array}$ & $\begin{array}{c}\text { Risk } \\
\text { coeffi- } \\
\text { cient }(\sigma) \\
\text { for } \\
\text { ordinary } \\
\text { player }\end{array}$ & $\begin{array}{c}\text { Risk } \\
\text { coeffi- } \\
\text { cient } \\
(\sigma) \\
\text { for } \\
\text { leader }\end{array}$ & $\begin{array}{l}\text { Brief } \\
\text { descrip- } \\
\text { tion for } \\
\text { ordinary } \\
\text { player }\end{array}$ & $\begin{array}{c}\text { Brief } \\
\text { descrip- } \\
\text { tion } \\
\text { for } \\
\text { leader* }\end{array}$ \\
\hline \multirow{2}{*}{10} & A & $\begin{array}{c}24.3 \\
8.7\end{array}$ & $\begin{array}{l}7.7 \\
3.1\end{array}$ & $\begin{array}{l}8.9 \\
2.5\end{array}$ & $\begin{array}{l}1 / 3 \\
2 / 3\end{array}$ & 4.6 & 4.6 & \multirow{2}{*}{0} & \multirow{2}{*}{0} & 2.2 & 3.0 & HR/SP & HR/SP \\
\hline & B & $\begin{array}{l}10.7 \\
15.5\end{array}$ & $\begin{array}{l}4.3 \\
4.8\end{array}$ & $\begin{array}{l}2.1 \\
5.9\end{array}$ & $\begin{array}{l}1 / 3 \\
2 / 3\end{array}$ & 4.6 & 4.6 & & & 0.2 & 1.8 & LR/SP & LR/SP \\
\hline \multirow{2}{*}{11} & A & $\begin{array}{c}27.8 \\
3.7\end{array}$ & $\begin{array}{l}8.9 \\
1.5 \\
\end{array}$ & $\begin{array}{l}10 \\
0.7 \\
\end{array}$ & $\begin{array}{l}1 / 3 \\
2 / 3\end{array}$ & 4.0 & 3.8 & \multirow[t]{2}{*}{1} & \multirow{2}{*}{1} & 3.5 & 4.4 & HR/HP & HR/LP \\
\hline & B & $\begin{array}{c}7.8 \\
12.2 \\
\end{array}$ & $\begin{array}{c}2.9 \\
3\end{array}$ & $\begin{array}{c}2 \\
6.2\end{array}$ & $\begin{array}{l}1 / 3 \\
2 / 3\end{array}$ & 3.0 & 4.8 & & & 0.0 & 2.0 & LR/LP & LR/HP \\
\hline \multirow{2}{*}{12} & A & $\begin{array}{c}30.6 \\
6.6\end{array}$ & $\begin{array}{c}10.1 \\
2.9\end{array}$ & $\begin{array}{c}10.4 \\
0.8\end{array}$ & $\begin{array}{l}1 / 3 \\
2 / 3\end{array}$ & 5.3 & 4 & & & 3.4 & 4.5 & HR/HP & HR/LP \\
\hline & B & $\begin{array}{c}9 \\
14.4\end{array}$ & $\begin{array}{l}3.1 \\
3.4\end{array}$ & $\begin{array}{l}2.8 \\
7.6\end{array}$ & $\begin{array}{l}1 / 3 \\
2 / 3\end{array}$ & 3.3 & 6 & 2 & 2 & 0.1 & 2.3 & LR/LP & LR/HP \\
\hline & A & $\begin{array}{c}31 \\
10.4\end{array}$ & $\begin{array}{c}10.2 \\
4.9\end{array}$ & $\begin{array}{c}10.6 \\
0.6\end{array}$ & $\begin{array}{l}1 / 3 \\
2 / 3\end{array}$ & 6.7 & 3.9 & & & 2.5 & 4.7 & HR/HP & HR/LP \\
\hline 13 & B & $\begin{array}{c}8.2 \\
17.3\end{array}$ & $\begin{array}{l}3 \\
4\end{array}$ & $\begin{array}{l}2.2 \\
9.3\end{array}$ & $\begin{array}{l}1 / 3 \\
2 / 3\end{array}$ & 3.7 & 6.9 & 3 & 3 & 0.5 & 3.3 & LR/LP & LR/HP \\
\hline
\end{tabular}

*Abbreviations: HR- relatively high risk; LR - relatively low risk; HP - relatively high expected payoff; LP - relatively low expected payoff; SP the same expected profit as the alternative lottery. (Experimental participants receive information contained only in columns 3-6). 
Table 1 [D] Seesaw Lottery Pairs

\begin{tabular}{|c|c|c|c|c|c|c|c|c|c|c|c|c|c|}
\hline $\begin{array}{l}\text { Lottery } \\
\text { pair ID }\end{array}$ & $\begin{array}{l}\text { Lottery } \\
\text { ID }\end{array}$ & $\begin{array}{l}\text { Team } \\
\text { payoff }\end{array}$ & $\begin{array}{c}\text { Ordinary } \\
\text { player's } \\
\text { payoff }\end{array}$ & $\begin{array}{c}\text { Leader's } \\
\text { payoff }\end{array}$ & $\begin{array}{l}\text { Proba- } \\
\text { bility }\end{array}$ & $\begin{array}{l}\text { Expected } \\
\text { payoff of } \\
\text { the } \\
\text { lottery } \\
\text { for } \\
\text { ordinary } \\
\text { player }\end{array}$ & $\begin{array}{l}\text { Expected } \\
\text { payoff } \\
\text { of } \\
\text { the } \\
\text { lottery } \\
\text { for } \\
\text { leader }\end{array}$ & $\begin{array}{c}\text { Absolute } \\
\text { difference } \\
\text { in expected } \\
\text { payoffs } \\
\text { between } \\
\text { two } \\
\text { lotteries for } \\
\text { ordinary } \\
\text { player }\end{array}$ & $\begin{array}{c}\text { Absolute } \\
\text { difference } \\
\text { in } \\
\text { expected } \\
\text { payoffs } \\
\text { between } \\
\text { two } \\
\text { lotteries } \\
\text { for leader }\end{array}$ & $\begin{array}{l}\text { Risk } \\
\text { coeffi- } \\
\text { cient }(\sigma) \\
\text { for } \\
\text { ordinary } \\
\text { player }\end{array}$ & $\begin{array}{l}\text { Risk } \\
\text { coeffi- } \\
\text { cient } \\
(\sigma) \\
\text { for } \\
\text { leader }\end{array}$ & $\begin{array}{l}\text { Brief } \\
\text { descrip- } \\
\text { tion for } \\
\text { ordinary } \\
\text { player }\end{array}$ & $\begin{array}{c}\text { Brief } \\
\text { descrip- } \\
\text { tion } \\
\text { for } \\
\text { leader* }\end{array}$ \\
\hline \multirow{2}{*}{14} & A & $\begin{array}{c}13.5 \\
6\end{array}$ & $\begin{array}{c}4.5 \\
2\end{array}$ & $\begin{array}{c}4.5 \\
2\end{array}$ & $\begin{array}{l}1 / 3 \\
2 / 3\end{array}$ & 2.8 & 2.8 & \multirow{2}{*}{1.5} & \multirow{2}{*}{3} & 1.2 & 1.2 & HR/HP & LR/LP \\
\hline & B & $\begin{array}{c}10.6 \\
4.3\end{array}$ & $\begin{array}{l}1.7 \\
0.6\end{array}$ & $\begin{array}{l}7.2 \\
3.1\end{array}$ & $\begin{array}{l}2 / 3 \\
1 / 3\end{array}$ & 1.3 & 5.8 & & & 0.5 & 1.9 & LR/LP & HR/HP \\
\hline \multirow[b]{2}{*}{15} & A & 21 & 4.5 & $\frac{12}{5}$ & $1 / 3$ & 2.8 & 7.3 & \multirow[b]{2}{*}{1.5} & \multirow[b]{2}{*}{3} & 1.2 & 3.3 & HR/LP & $\mathrm{HR} / \mathrm{HP}$ \\
\hline & B & $\begin{array}{c}9 \\
15\end{array}$ & 3 & $\begin{array}{l}3 \\
5\end{array}$ & $\begin{array}{l}1 / 3 \\
2 / 3\end{array}$ & 4.3 & 4.3 & & & 0.9 & 0.9 & LR/HP & LR/LP \\
\hline \multirow{2}{*}{16} & A & $\begin{array}{c}10.5 \\
6.6\end{array}$ & $\begin{array}{l}3.5 \\
2.2\end{array}$ & $\begin{array}{l}3.5 \\
2.2\end{array}$ & $\begin{array}{l}1 / 3 \\
2 / 3\end{array}$ & 2.6 & 2.6 & \multirow{2}{*}{3} & \multirow{2}{*}{1.5} & 0.6 & 0.6 & LR/LP & HR/HP \\
\hline & B & $\begin{array}{c}8.6 \\
14.3\end{array}$ & $\begin{array}{l}4.1 \\
6.4\end{array}$ & $\begin{array}{l}0.4 \\
1.5\end{array}$ & $\begin{array}{l}1 / 3 \\
2 / 3\end{array}$ & 5.6 & 1.1 & & & 1.1 & 0.5 & HR/HP & LR/LP \\
\hline 17 & A & $\begin{array}{l}20.9 \\
11.3\end{array}$ & $\begin{array}{l}9.2 \\
4.9\end{array}$ & $\begin{array}{l}2.5 \\
1.5\end{array}$ & $\begin{array}{l}1 / 3 \\
2 / 3\end{array}$ & 6.3 & 1.8 & 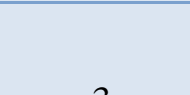 & & 2.0 & 0.5 & HR/HP & LR/LP \\
\hline $1 /$ & B & $\begin{array}{c}6 \\
12\end{array}$ & $\begin{array}{l}2 \\
4\end{array}$ & $\begin{array}{l}2 \\
4\end{array}$ & $\begin{array}{l}1 / 3 \\
2 / 3\end{array}$ & 3.3 & 3.3 & 3 & 1.5 & 0.9 & 0.9 & LR/LP & HR/HP \\
\hline
\end{tabular}

*Abbreviations: HR- relatively high risk; LR - relatively low risk; HP - relatively high expected payoff; LP - relatively low expected payoff; SP the same expected profit as the alternative lottery. (Experimental participants receive information contained only in columns 3-6). 


\begin{tabular}{|c|c|c|}
\hline $\begin{array}{c}\text { One member in a } \\
\text { team of three players } \\
\text { becomes a leader. } \\
\text { The leader is determined } \\
E X \text { treatment: by random draw; } \\
\text { EN treatment : by majority voting }\end{array}$ & $\begin{array}{l}\text { A team receives a decision } \\
\text { problem (lottery pair) and } \\
\text { all members of the team, } \\
\text { including the leader, cast } \\
\text { their vote for one of the } \\
\text { two available alternatives } \\
\text { (lotteries). }\end{array}$ & $\begin{array}{l}\text { The leader observes the result of the } \\
\text { majority voting and decides either to } \\
\text { confirm (democratic decision) or to } \\
\text { alter (autocratic decision) the team } \\
\text { majority decision. This decision along } \\
\text { with the team majority decision is } \\
\text { reported to all team members. }\end{array}$ \\
\hline$t=0$ & $t=2 s-1$ & $t=2 s$ \\
\hline & TIME & \\
\hline $\begin{array}{c}S=0 \\
\text { Determination of the leader }\end{array}$ & \multicolumn{2}{|c|}{$\begin{array}{c}s \in\{1, \ldots, 17\} \\
\text { Decision problems }\end{array}$} \\
\hline
\end{tabular}

Figure 1 Timeline of the Team Task

Table 2 Treatments and Sequences of the Experiment

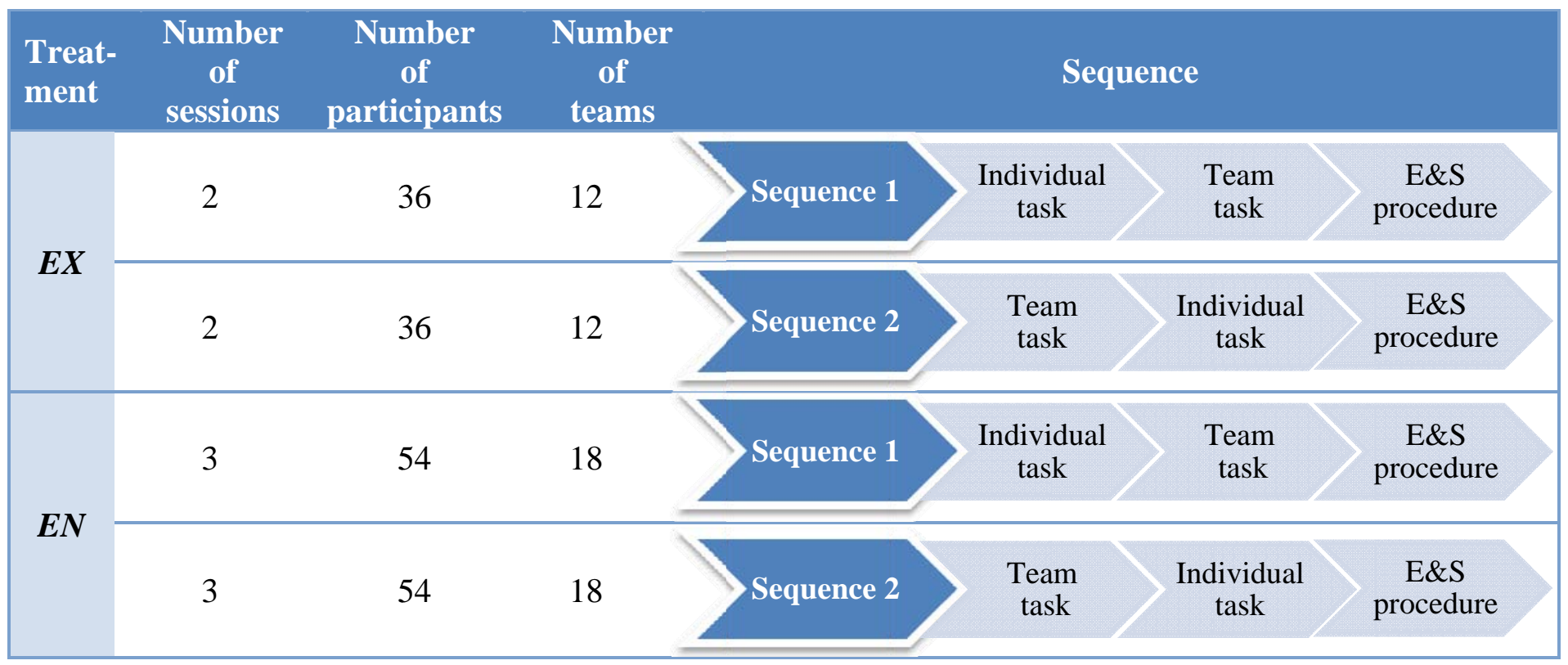


Table 3 Average (Median) Payoffs in the Experiment

\begin{tabular}{|c|c|c|c|c|c|c|}
\hline Decision type & $\begin{array}{l}\text { Team } \\
\text { actual } \\
\text { payoff }\end{array}$ & $\begin{array}{c}\text { Team } \\
\text { alternative } \\
\text { payoff* }\end{array}$ & $\begin{array}{c}\text { Leader's } \\
\text { actual } \\
\text { payoff }\end{array}$ & $\begin{array}{l}\text { Leader's } \\
\text { alternative } \\
\text { payoff* }\end{array}$ & $\begin{array}{l}\text { Ordinary } \\
\text { player's } \\
\text { actual } \\
\text { payoff }\end{array}$ & $\begin{array}{l}\text { Ordinary } \\
\text { player's } \\
\text { alternative } \\
\text { payoff* }\end{array}$ \\
\hline $\begin{array}{c}\text { Democratic } \\
\text { decisions }\end{array}$ & $\begin{array}{c}13.02 \\
(12.45)\end{array}$ & $\begin{array}{c}17.50 \\
(15.25)\end{array}$ & $\begin{array}{c}4.47 \\
(3.75)\end{array}$ & $\begin{array}{c}6.11 \\
(3.75)\end{array}$ & $\begin{array}{c}4.28 \\
(4.40)\end{array}$ & $\begin{array}{c}5.70 \\
(4.80)\end{array}$ \\
\hline $\begin{array}{c}\text { Autocratic } \\
\text { decisions }\end{array}$ & $\begin{array}{c}11.92 \\
(10.60)\end{array}$ & $\begin{array}{l}13.62 \\
(9.80)\end{array}$ & $\begin{array}{c}5.20 \\
(4.95)\end{array}$ & $\begin{array}{c}5.98 \\
(3.10)\end{array}$ & $\begin{array}{c}3.37 \\
(3.10)\end{array}$ & $\begin{array}{c}3.82 \\
(3.10)\end{array}$ \\
\hline $\begin{array}{c}\text { Two-sample } \\
\text { Wilcoxon-Mann- } \\
\text { Whitney } \\
\text { test probability }\end{array}$ & 0.5880 & 0.0699 & 0.1696 & 0.6319 & 0.0442 & 0.0024 \\
\hline
\end{tabular}

* Alternative payoff - the payoff that participants would have received had the lottery outcome been different.

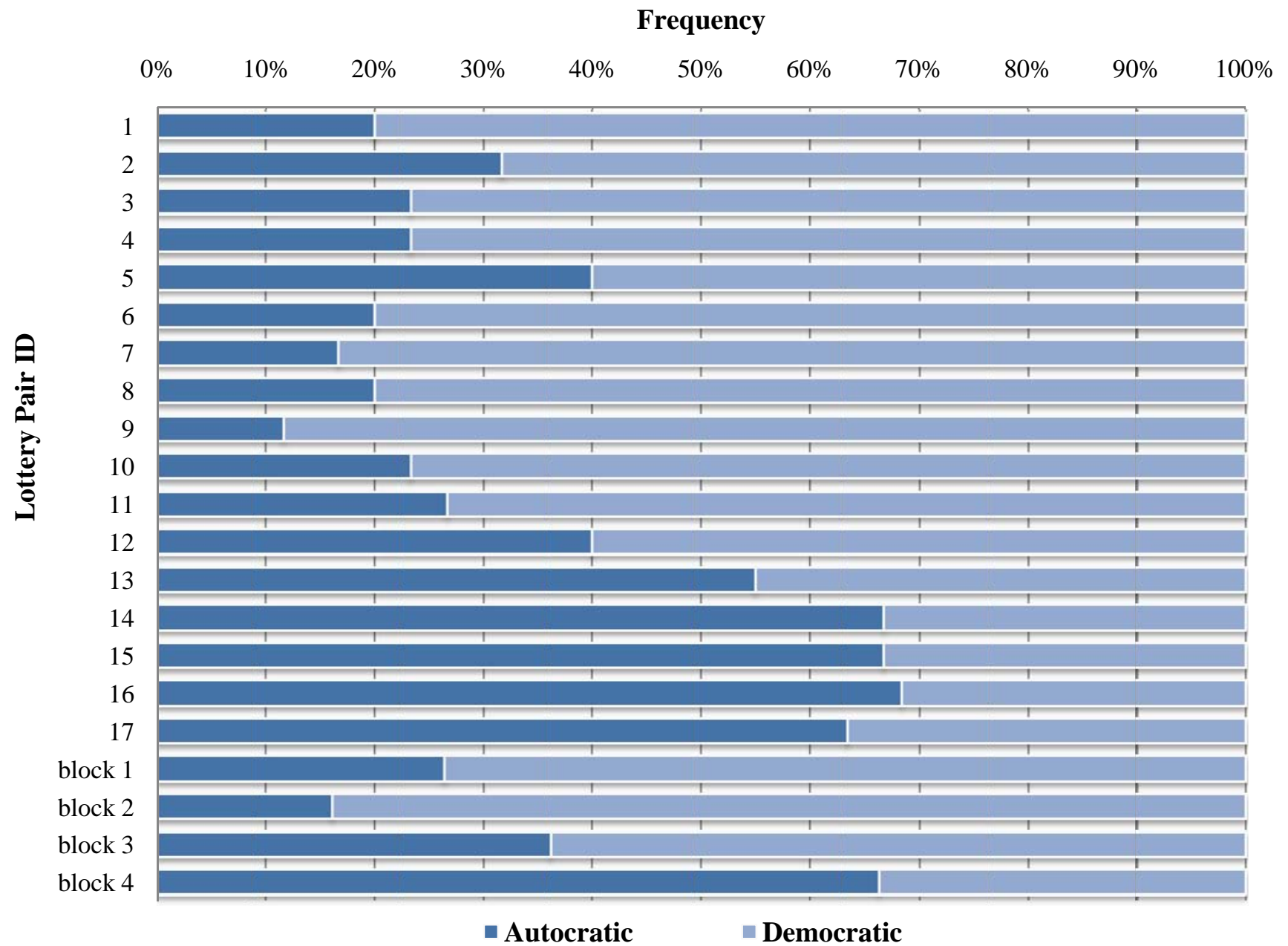

Figure 2 Autocratic and Democratic Decisions by Lottery Pair and Block 


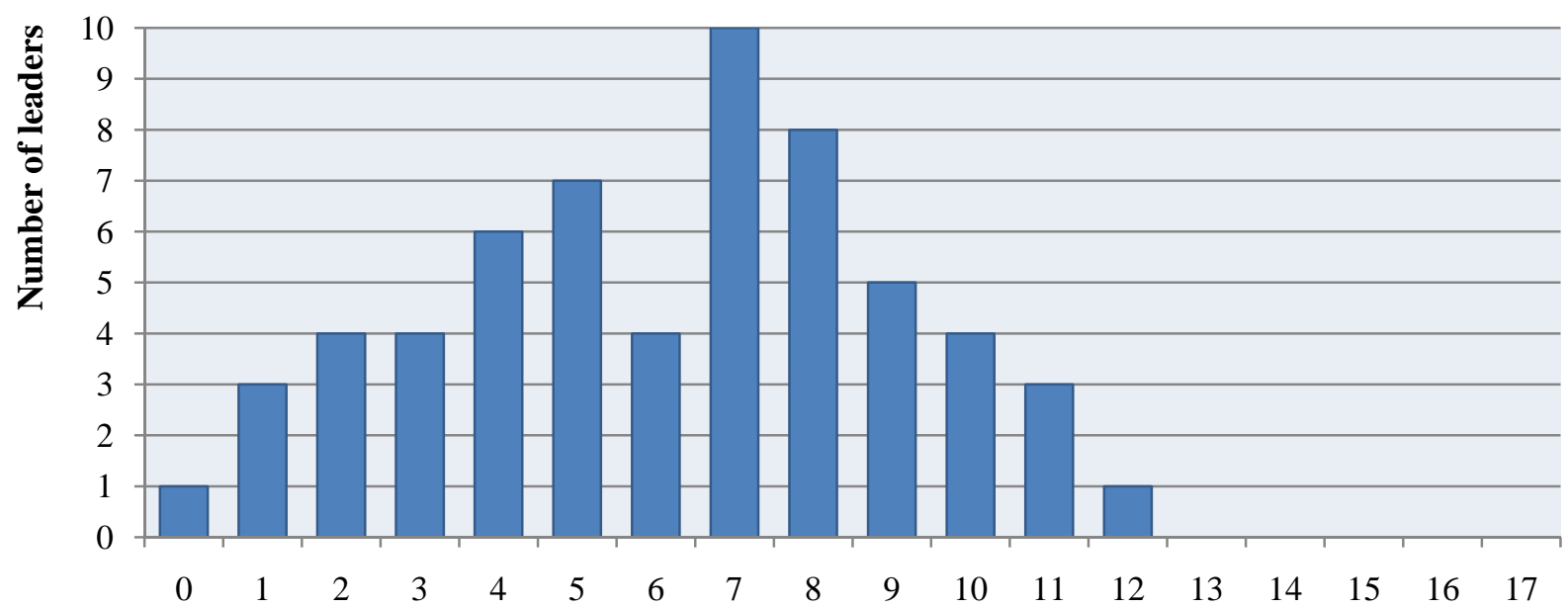

Number of autocratic decisions per leader

Figure 3 Autocratic and Democratic Decisions by Leader

Table 4 Autocratic and Democratic Decisions by Motive

\begin{tabular}{|c|c|c|c|}
\hline $\begin{array}{c}\text { Autocratic Decisions } \\
\text { Power } \\
\text { decisions }\end{array}$ & $\begin{array}{c}\text { Dissent } \\
\text { decisions }\end{array}$ & $\begin{array}{c}\text { Democratic } \\
\text { Consensus } \\
\text { decisions }\end{array}$ & $\begin{array}{c}\text { Decisions } \\
\text { Conformist } \\
\text { decisions }\end{array}$ \\
\hline 33 & 337 & 546 & 104 \\
$(3.2 \%)$ & $(33.0 \%)$ & $(53.5 \%)$ & $(10.2 \%)$ \\
\hline & 370 & & \multicolumn{3}{|c|}{$\begin{array}{c}650 \\
(36.3 \%)\end{array}$} & \multicolumn{3}{c|}{$(63.7 \%)$} \\
\hline
\end{tabular}

Table 5 Individual Other-Regarding Preferences, Derived from the E\&S Procedure (\% of population)

\begin{tabular}{|lcccccc|} 
& EF & ERC & F\&S & MM & Combination & None \\
\cline { 1 - 5 } Ordinary players: & 32.5 & 8.3 & 0.8 & 14.2 & 25.8 & 18.3 \\
\hline EX treatment & 37.5 & 6.3 & 2.1 & 12.5 & 29.2 & 12.5 \\
\hline EN treatment & 29.2 & 9.7 & 0.0 & 15.3 & 23.6 & 22.2 \\
\hline Leaders: & 36.7 & 1.7 & 1.7 & 6.7 & 25.0 & 28.3 \\
\hline EX treatment & 29.2 & 4.2 & 0.0 & 16.7 & 16.7 & 33.3 \\
\hline EN treatment & 41.7 & 0.0 & 2.8 & 0.0 & 30.6 & 25.0 \\
\hline All: & 33.9 & 6.1 & 1.1 & 11.7 & 25.6 & 21.7 \\
\hline EX treatment & 34.7 & 5.6 & 1.4 & 13.9 & 25.0 & 19.4 \\
\hline EN treatment & 33.3 & 6.5 & 0.9 & 10.2 & 25.9 & 23.1 \\
\hline
\end{tabular}


Table 6 Percentage of Inconsistent Decisions

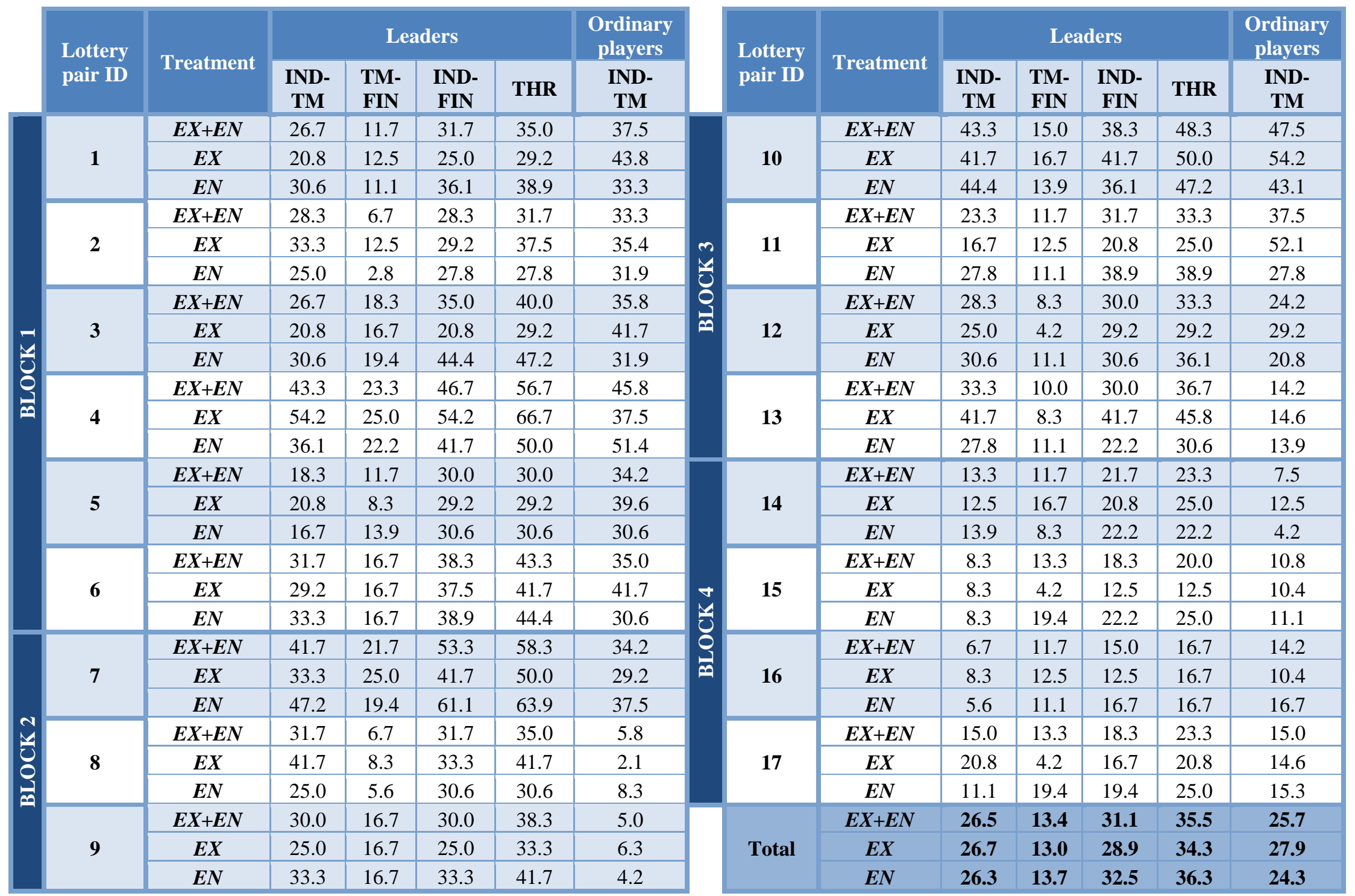

Abbreviations: IND-TM - percentage of inconsistent decisions between individual task and team vote in the team task;

TM-FIN - percentage of inconsistent decisions between voting in the team task and final decision;

IND-FIN - percentage of inconsistent decisions between individual task and final decision;

THR - number of inconsistent decisions throughout the experiment. 
Table 7 List of Explanatory Variables Used in the Econometric Analysis

\begin{tabular}{|c|c|}
\hline Explanatory variable & Description \\
\hline OPPREF 1 & Opposing preferences $1: 0$ - outcome of the team majority vote coincides with leader's vote in the team task; 1 - otherwise \\
\hline OPPREF 2 & $\begin{array}{l}\text { Opposing preferences 2: } 0 \text { - outcome of the team majority vote in the team task coincides with leader's choice in the individual task; } 1- \\
\text { otherwise }\end{array}$ \\
\hline CONS 1 & Consistency 1 dummy: 0 - leader has made the same choice in the individual task and team vote in the team task; 1 - otherwise \\
\hline CONS 2 & Consistency 2 dummy: 0 - leader has consistently chosen the same option in all decision tasks; 1 - otherwise \\
\hline EF & EF dummy: 0 - leader’s individual other-regarding preferences are inconsistent with efficiency preferences; 1 -otherwise \\
\hline MM & MM dummy: 0 - leader's individual other-regarding preferences are inconsistent with maximin preferences; 1 -otherwise \\
\hline TREATMENT & Treatment dummy: $0-E X$ treatment; $1-E N$ treatment \\
\hline SEQUENCE & Sequence dummy: 0 - Sequence $1 ; 1$ - Sequence 2 \\
\hline VATTEMPT & $\begin{array}{l}\text { Voting attempt: } 0 \text { - leader has been assigned exogenously; } 1 \text { - leader has been elected during the } 1^{\text {st }} \text { attempt; } 2-\text { during the } 2^{\text {nd }} \text { attempt; } \\
3 \text { - during the } 3^{\text {rd }} \text { attempt; } 4 \text {-leader has been assigned exogenously because the team has failed to elect a leader. }\end{array}$ \\
\hline GENDER & Gender dummy: Self-reported gender: 0 - male; 1 -female \\
\hline AGE & Age: Self-reported age \\
\hline MAJOR & Study dummy: Self-reported major: 0 - other than economics or business administration; 1 - economics or business administration; \\
\hline MOOD 1 & Mood 1: Self-reported mood on the day of the experiment on a scale from 1 - "very bad" to 5 - "very good" \\
\hline MOOD 2 & Mood 2: Self-reported mood during the experiment on a scale from 1 - "very bad" to 5 - "very good" \\
\hline EXPERIENCE & $\begin{array}{l}\text { Experience: Self-reported experience with economic experiments: } 0 \text { - never before; } 1 \text { - once before; } 2 \text { - from } 2 \text { to } 5 \text { times; } 3 \text { - more } \\
\text { often }\end{array}$ \\
\hline ACQUAINTANCES & Acquaintances: Self-reported number of other participants in the sessions that an experimental participant knows personally \\
\hline OVERCONF 1 & $\begin{array}{l}\text { Overconfidence 1: Self-reported assessment of participants' personal performance in the standard intelligence test versus other } \\
\text { experimental participants in the session: } 1 \text { - place } 1-3 ; 2 \text { - place } 4-6 ; 3 \text { - place } 7-9 ; 4 \text { - place } 10-12 ; 5 \text { - place } 13-15 ; 6 \text { - place } 16-18\end{array}$ \\
\hline OVERCONF 2 & Overconfidence 2: Same as Overconfidence 1 only the test is in participant’s field of study \\
\hline MATH & Mathematics skills: Self-reported high school/university grade in mathematics from 5 - "excellent" to 1 - "incomplete" \\
\hline ERAR & $\begin{array}{c}\text { Elicited risk attitude rank: Risk attitude rank based on the number of safe choices in the Holt and Laury (2002) risk attitude elicitation } \\
\text { procedure from } 0 \text { - "highly risk seeking" to } 10 \text { - "extremely risk averse" }\end{array}$ \\
\hline MACH & Machiavelli rank: Ranking of participants according to the Machiavelli V scale from 1 - "very selfish" to 7 - "very altruistic". \\
\hline PROMISE & Promise dummy: 0 - leader has not promised to confirm team’s decisions in the election chat; 1 - otherwise \\
\hline ERC & ERC dummy: 0 - leader's individual other-regarding preferences are inconsistent with ERC preferences; 1 -otherwise \\
\hline$F \& S$ & F\&S dummy: 0 - leader’s individual other-regarding preferences are inconsistent with F\&S preferences; 1 -otherwise \\
\hline SESSION & Session: Session identifier from 0 to 9 \\
\hline SRAR & Self-reported risk attitude rank: Self-reported risk attitude from 0 - "very risk seeking”; to 7 - "very risk averse" \\
\hline TGENDER & Team gender: Team gender identifier between 0 - no women and 3 - all women \\
\hline TSTUDY & $\begin{array}{l}\text { Team study: Team major identifies from } 0 \text { - no one of the team members studies economics or business administration to } 3 \text { - all team } \\
\text { members study economics or business administration }\end{array}$ \\
\hline
\end{tabular}


Table 8 Results of the Random Intercept Logit Estimation

\begin{tabular}{|c|c|c|c|c|c|c|c|c|}
\hline \multirow{4}{*}{$\begin{array}{l}\text { Explanatory variable } \\
\text { CONSTANT }\end{array}$} & \multicolumn{8}{|c|}{ Dependent variable } \\
\hline & \multicolumn{8}{|c|}{$\begin{array}{c}\text { Autocratic decision }\left(y_{i}^{l}=1\right) \text {, Democratic decision }\left(y_{i}^{l}=0\right) \\
\text { Marginal effect (standard error) }\end{array}$} \\
\hline & Two-level model 1 & Two-level model 2 & \multicolumn{2}{|c|}{ Two-level model 3} & \multicolumn{2}{|c|}{ Two-level model 4} & \multicolumn{2}{|c|}{ Three-level model } \\
\hline & $-2.8868 * * * \quad(0.2639)$ & $-2.4695 * * * \quad(0.3542)$ & -0.9647 & $(1.7361)$ & -1.7817 & $(1.6887)$ & -1.8244 & $(1.8236)$ \\
\hline OPPREF 1 & $3.8513 * * * \quad(0.3241)$ & $3.8580 * * * \quad(0.3251)$ & $3.8203^{* * *}$ & $(0.3266)$ & $3.8043^{* * *}$ & $(0.3223)$ & $3.8217 * * *$ & $(0.3241)$ \\
\hline OPPREF 2 & $1.7072 * * * \quad(0.2888)$ & $1.7100 * * * \quad(0.2899)$ & $1.7053^{* * *}$ & $(0.2906)$ & $1.7966 * * *$ & $(0.2909)$ & $1.7795^{* * *}$ & $(0.2921)$ \\
\hline CONS 1 & $-2.3559 * * * \quad(0.4102)$ & $-2.3105^{* * *} \quad(0.4083)$ & $-2.3183^{* *}$ & $(0.4115)$ & $-2.2797 * * *$ & $(0.4136)$ & $-2.2638 * *$ & ${ }^{*}(0.4141)$ \\
\hline CONS 2 & $(0.3817)$ & $(0.3808)$ & -0.4981 & $(0.3811)$ & -0.5494 & $(0.3838)$ & -0.5388 & $(0.3845)$ \\
\hline$E F$ & - & $(0.3021)$ & $0.6350 *$ & $(0.3224)$ & $0.8479 * *$ & $(0.3278)$ & & \\
\hline MM & - & $(0.5877)$ & -0.0870 & $(0.5989)$ & -0.1466 & $(0.5807)$ & -0.2352 & $(0.5992)$ \\
\hline TREATMENT & - & $-0.7599 *$ & -0.4365 & $(0.6603)$ & $-1.7564 *$ & $(0.8504)$ & $-1.7230 *$ & $(0.8650)$ \\
\hline SEQUENCE & - & $(0.2846)$ & -0.1344 & $(0.2931)$ & -0.5116 & $(0.3853)$ & -0.5578 & $(0.3963)$ \\
\hline VATTEMPT & - & - & 0.0647 & $(0.1880)$ & 0.2456 & (0.1966) & 0.2562 & $(0.2006)$ \\
\hline GENDER & - & - & 0.1985 & $(0.3088)$ & $0.7477^{*}$ & $(0.3712)$ & 0.7269 & $(0.3800)$ \\
\hline$A G E$ & - & - & 0.0263 & $(0.0597)$ & 0.0517 & $(0.0595)$ & 0.0578 & $(0.0613)$ \\
\hline MAJOR & - & - & 0.0198 & $(0.2977)$ & -0.1326 & $(0.4152)$ & -0.2033 & $(0.4281)$ \\
\hline MOOD 1 & - & - & -0.3255 & $(0.2414)$ & -0.3138 & $(0.2265)$ & -0.2820 & $(0.2320)$ \\
\hline MOOD 2 & - & - & -0.1302 & $(0.2817)$ & -0.1545 & $(0.2705)$ & -0.0966 & $(0.2817)$ \\
\hline EXPERIENCE & - & - & -0.0263 & $(0.2149)$ & 0.0427 & $(0.2132)$ & 0.0144 & $(0.2192)$ \\
\hline ACQUAINTANCES & - & - & -0.0992 & $(0.2137)$ & 0.0782 & $(0.2136)$ & 0.1194 & $(0.2203)$ \\
\hline OVERCONF 1 & - & - & -0.0608 & $(0.1490)$ & -0.1713 & $(0.1475)$ & -0.1654 & $(0.1503)$ \\
\hline OVERCONF 2 & - & - & -0.0875 & $(0.1333)$ & -0.0830 & $(0.1271)$ & -0.0768 & $(0.1297)$ \\
\hline MATH & - & - & 0.0405 & $(0.1449)$ & -0.0322 & $(0.1362)$ & -0.0080 & $(0.1407)$ \\
\hline ERAR & - & - & 0.0901 & $(0.0984)$ & 0.0931 & $(0.0966)$ & 0.0800 & $(0.0992)$ \\
\hline МАСН & - & - & -0.1889 & $(0.1098)$ & $-0.2073 *$ & $(0.1040)$ & -0.1971 & $(0.1066)$ \\
\hline PROMISE & - & - & -0.4768 & $(0.5068)$ & -0.5628 & $(0.5024)$ & -0.5359 & $(0.5122)$ \\
\hline ERC & - & - & & & 1.3780 & $(1.0173)$ & 1.2191 & $(1.0539)$ \\
\hline$F \& S$ & - & - & & & -1.6879 & $(1.2636)$ & -1.9685 & (1.3128) \\
\hline SESSION & - & - & & & 0.2440 & $(0.1306)$ & 0.2330 & $(0.1332)$ \\
\hline SRAR & - & - & & & 0.2219 & $(0.1438)$ & 0.1930 & $(0.1494)$ \\
\hline TGENDER & - & - & & & -0.4044 & $(0.2126)$ & -0.3974 & $(0.2169)$ \\
\hline TSTUDY & - & - & & & -0.0265 & $(0.2076)$ & 0.0221 & $(0.2156)$ \\
\hline Log-likelihood $(L L)$ & -282.93 & -279.06 & -27 & & -268. & & -27 & .22 \\
\hline Number of level 1 units (leaders’ final decisions) & 1020 & 1020 & & & 102 & & 10 & \\
\hline Number of level 2 units (individual leaders) & 60 & 60 & & & 60 & & & \\
\hline Standard deviation (standard error) for the random intercept at level 2 & $0.7428(0.1002)$ & $0.6268(0.0763)$ & 0.4505 & $.0440)$ & $0.1641(0$ & $0.0129)$ & 0.2531 & $0.0217)$ \\
\hline Number of level 3 units (EF dummy) & - & - & & & - & & & \\
\hline Standard deviation (standard error) for the random intercept at level 3 & - & - & & & - & & 0.3067 & $0.0237)$ \\
\hline
\end{tabular}

* - significant at 0.05 level;** - significant at 0.01 level; *** - significant at 0.001 level 
Table 9 Results of the Random Intercept Multinomial Logit Estimation

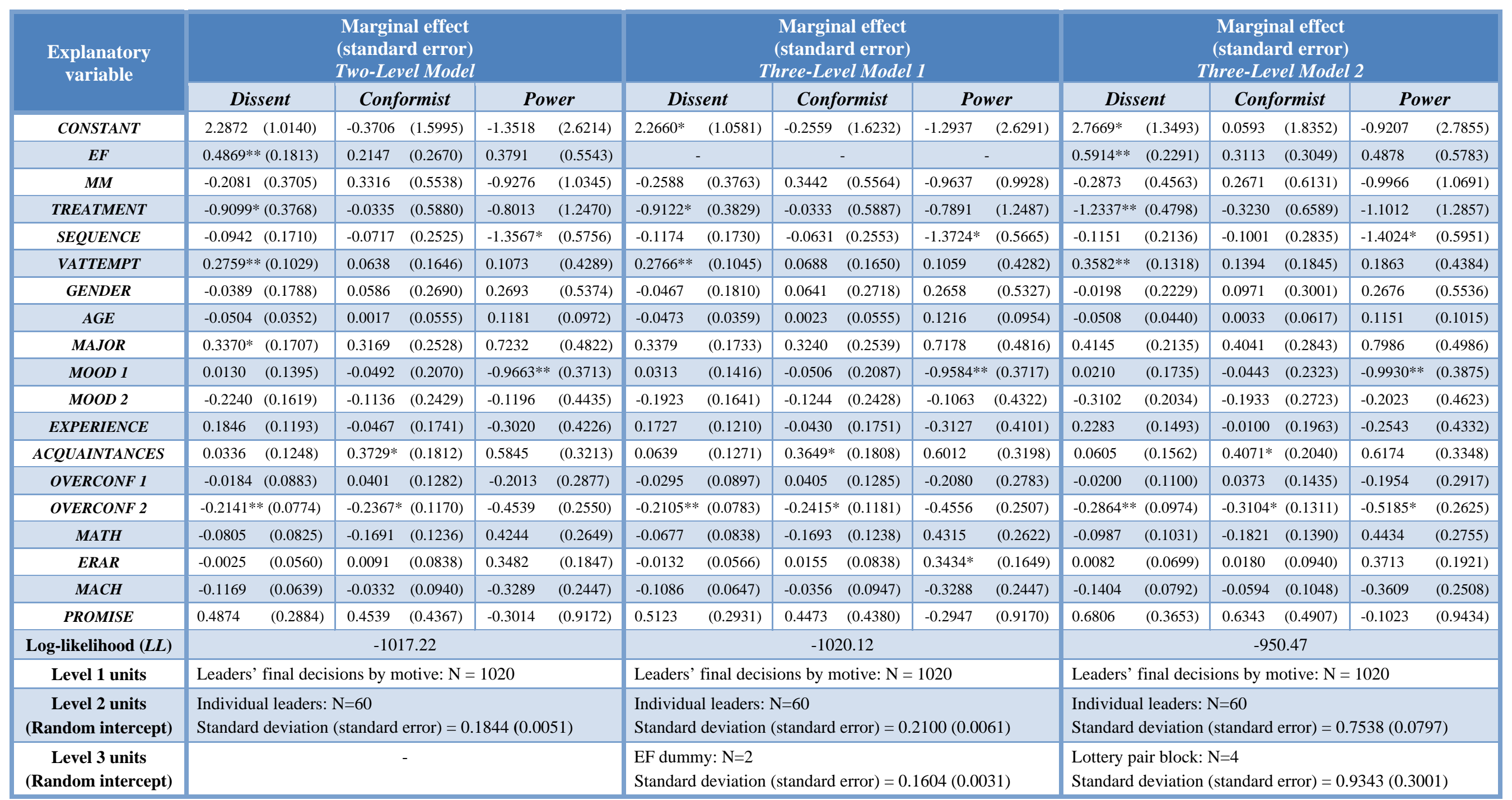

* - significant at 0.05 level; ** - significant at 0.01 level; *** - significant at 0.001 level 


\section{REFERENCES}

Ahmed S. M. S. and R. A. C. Stewart (1981) "Factor Analysis of the Machiavellian Scale." Social Behavior and Personality, 9(1), pp. 113-115.

Andreoni, J. (2006) “Leadership Giving in Charitable Fund-raising.” Journal of Public Economic Theory, 8(1), pp. 1-22.

Bolton, G. E., Katok, E. and R. Zwick (1998) "Dictator Game Giving: Rules of Fairness versus Acts of Kindness.” International Journal of Game Theory, 27(2), pp. 269-299.

Bolton, G. E., Ockenfels, A. (2000) "ERC - A Theory of Equity, Reciprocity and Competition.” American Economic Review 90(1), pp. 166-193.

Bolton, G. E., Ockenfels, A. (2006) "Inequality Aversion, Efficiency, and Maximin Preferences in Simple Distribution Experiments: Comment.” American Economic Review 96(5), pp. 1906-1911.

Burks, S. V., Carpenter, J. P. and E. Verhoogen (2003) "Playing Both Roles in the Trust Game.” Journal of Economic Behavior and Organization, 51(2), pp. 195-216.

Charness, G. and M. Rabin (2002) "Understanding Social Preferences with Simple Tests." Quarterly Journal of Economics, 117(3), pp. 817-869.

Charness, G. and M. Rabin (2005) "Expressed Preferences and Behavior in Experimental Games." Games and Economic Behavior, 53(2), pp. 151-169.

Charness, G., Rigotti, L. and A. Rustichini (2007) "Individual Behavior and Group Membership.” American Economic Review, 97(4), pp. 1340-1352.

Chen, Y. and S. X. Li "Group Identity and Social Preferences." American Economic Review, forthcoming.

Christie, R. and F. Gies (1970) Studies in Machiavellism, Academic Press, New York.

Davis, J. (1992) "Some Compelling Intuitions about Group Consensus Decisions, Theoretical and Empirical Research and Interpersonal Aggregation Phenomena: Selected Examples 1950 - 1990.” Organizational Behavior and Human Decision Processes, 52(1), pp. 3-38.

Engelmann, D. and M. Strobel (2004) "Inequality Aversion, Efficiency, and Maximin Preferences in Simple Distribution Experiments.” American Economic Review, 94(4), pp. 857-869.

Fehr, E. and K. Schmidt (1999) "A Theory of Fairness, Competition, and Cooperation." Quarterly Journal of Economics 114(3), pp. 817-868. 
Fehr, E., Naef, M., Schmidt, K. (2006) "Inequality Aversion, Efficiency, and Maximin Preferences in Simple Distribution Experiments: Comment.” American Economic Review 96(5), pp. 1912-1917.

Fischbacher, U. (2007) “z-Tree: Zurich Toolbox for Ready-made Economic Experiments.” Experimental Economics, 10(2), pp. 171-178.

Fisher, R. A. (1922) “On the Interpretation of $\chi^{2}$ from Contingency Tables, and the Calculation of p.” Journal of the Royal Statistical Society, 85, pp. 87-94.

Forsythe, R., Horowitz, J. L., Savin, N. E. and M. Sefton (1994) “Fairness in Simple Bargaining Experiments.” Games and Economic Behavior, 6(3), pp. 347-369.

Gächter, S., Nosenzo, D., Renner, E., Sefton, M. (2008) "Who Makes a Good Leader? Social Preferences and Leading-by-example.” CeDEx Discussion Paper No. 2008-16, University of Nottingham.

Gunnthorsdottir, A., McCabe, K. and V. Smith (2002) "Using the Machiavellianism Instrument to Predict Trustworthiness in a Bargaining Game.” Journal of Economic Psychology, 23(1), pp. 49-66.

Güth, W., Levati, V., Sutter, M. and van der Heijden, E. (2007) "Leading by Example with and without Exclusion Power in Voluntary Contribution Experiments." Journal of Public Economics, 91(5-6), pp. 1023-1042.

Haan, P. and A. Uhlendorff (2006) "Estimation of Multinomial Logit Models with Unobserved Heterogeneity Using Maximum Simulated Likelihood.” Stata Journal, 6(2), pp. 229-245.

Hey, J.D. and Ch. Orme (1994) "Investigating Generalizations of Expected Utility Theory Using Experimental Data.” Econometrica, 62(6), pp. 1291-1326.

Hollander, E. P. (1986) “On the Central Role of Leadership Processes.” International Review of Applied Psychology, 35(1), pp. 39-52.

Holt, C.A. and S. K. Laury (2002) "Risk Aversion and Incentive Effects.” American Economic Review, 92(5), pp. 1644-1655.

Knott, A. M. (2001) “The Dynamic Value of Hierarchy.” Management Science, 47(3), pp. 430448.

Komai, M., Stegeman, M. and B. Hermalin (2007) “Leadership and Information.” American Economic Review, 97(3), pp. 944-947.

Lewin, K., Lippitt, R. and R. K. White (1939) "Patterns of Aggressive Behavior in Experimentally Created Social Climates.” Journal of Social Psychology, 10, pp. 271-301. 
Longford, N.T. (1994) "Logistic Regression with Random Coefficients." Computational Statistics and Data Analysis, 17(1), pp. 1-15.

Mann, H. B. and D. R. Whitney (1947) "On a Test of whether One of Two Random Variables Is Stochastically Larger than the Other.” Annals of Mathematical Statistics, 18, pp. 50-60.

Potters, J., Sefton, M. and L. Vesterlund (2005) "After You - Endogenous Sequencing in Voluntary Contribution Games.” Journal of Public Economics, 89(8), pp. 1399-1419.

Potters, J., Sefton, M. and L. Vesterlund (2007) "Leading-by-example and Signaling in Voluntary Contribution Games: An Experimental Study.” Economic Theory, 33(1), pp. 169182.

Rabe-Hesketh, S., Skrondal, A. and A. Pickles (2002) "Reliable Estimation of Generalised Linear Mixed Models Using Adaptive Quadrature.” Stata Journal, 2(1), pp. 1-21.

Rotemberg, J. and G. Saloner (1993) "Leadership Style and Incentives.” Management Science, 39(11), pp. 1299-1318.

Smith, A. (1759) The Theory of Moral Sentiments, reprint Prometheus Books, 2000, Amherst, New York.

Sutter, M. "Individual Behavior and Group Membership: Comment." American Economic Review, forthcoming.

Van Vugt, M., Jepson, S., Hart, C., and D. De Cremer (2004) "Autocratic Leadership in Social Dilemmas: A Threat to Group Stability.” Journal of Experimental and Social Psychology, 40(1), pp. 1-13.

Vecchio, R. P. and M. Sussmann (1991) "Choice of Influence Tactics: Individual and Organizational Determinants.” Journal of Organizational Behavior, 12(1), pp. 73-80.

Vesterlund, L. (2003) "The Informational Value of Sequential Fundraising." Journal of Public Economics 87(3-4), pp. 627-657.

Wilcoxon, F. (1945) “Individual Comparisons by Ranking Methods.” Biometrics Bulletin, 1(6), pp. 80-83.

Wu, G., Zhang, J. and R. Gonzalez (2004) "Decision Under Risk” in Blackwell Handbook of Judgment and Decision Making, N. Harvey and D. Koehler eds., pp. 399-423. 


\title{
SUPPLEMENTARY MATERIAL (NOT INTENDED FOR PUBLICATION)
}

\section{“Other-Regarding PREFERENCES AND LEADERSHip STYLES”}

\author{
Appendix A

\section{Sample Experimental Instructions}

Dear participant,

Welcome to our experiment on decision making! If you carefully follow these simple instructions, you will earn a considerable amount of money. The money you will earn in this experiment is yours to keep and will be paid to you privately and in cash at the end of the experiment. The experiment will last approximately 1.5 hours.

The experiment consists of three parts. The instructions for Part 1 are given below. You will receive instructions for Part 2 after you have completed Part 1 and instructions for Part 3 after you have completed Part 2. These instructions will be read to you aloud and then you will have an opportunity to study them on your own. If you have a question about the content of the instructions, please raise your hand and the experimenter will answer your question in private. Please do not talk or communicate with other participants during the experiment. Irrespective of your performance in the experiment, you will be paid a show-up fee of $€ 3.00$.

Good luck and thank you for your participation!

\section{Part 1 (Individual task)}

You will be given $\mathbf{4 4}$ problems. These problems will appear on three consecutive computer screens. The first screen will display 17 problems, the second screen -10 problems and the third screen - 17 problems. In each problem you need to choose between two lotteries. Please, take your time and read each problem carefully. The example of a typical problem is given below:

\section{Sample Problem 12}

\begin{tabular}{ccc|} 
Lottery $\mathbf{X}$ & Lottery $\mathbf{Y}$ & Your choice is \\
You receive & You receive & Lottery $\mathbf{X}$ \\
$€ 9$ with probability $1 / 3$ or & $€ 3$ with probability $1 / 3$ or \\
$€ 2$ with probability $2 / 3$ & $€ 4$ with probability $2 / 3$ \\
\hline
\end{tabular}

Your payoff in this part is determined at the end of Part 3 of the experiment, based on the outcome of the lotteries that you have chosen. First, the computer program will generate a random number from 1 to 44 . This number will determine one of 44 problems. This problem (together with your choice) will reappear on your computer screen. Then the computer program will simulate the lottery you have chosen and reveal the outcome on your screen. The outcome of this lottery will determine your payoff. 
For example, suppose that the computer program has generated a random number 12 and problem 12 presented above reappears on your screen. And suppose that you have chosen Lottery $\mathrm{X}$ in this problem. Then the computer program will simulate Lottery $\mathrm{X}$ and reveal your payoff (either $€ 9$ or $€ 2$ ). Your payoff will be paid out in cash at the end of the experiment along with your earnings from Part 2 and Part 3.

\section{Part 2 (Team task)*}

Part 2 of the experiment consists of 17 rounds. At the beginning of Part 2 you will be randomly assigned to a team of $\mathbf{3}$ people by the computer program. The composition of your team will remain fixed for the duration of this part of the experiment. Each team should consist of two players of type 1 and one player of type 2. Initially, all players are assigned type 1 . You need to elect one member of the team to be a type 2 player.

Any member of the team can propose him- or herself as a candidate for becoming a type 2 player and specify reasons why he or she should be elected. You can communicate with other team members through the computer chat window. Type 2 player is elected by a simple majority voting (one needs 2 votes to be elected). Each team has 3 voting attempts to elect a type 2 player. If the team cannot choose a type 2 player during 3 attempts, the computer program will select a type 2 player at random. The difference between types is explained below. Type $\mathbf{2}$ player is chosen for the entire length of Part 2 and cannot be changed.

After a type 2 player is determined, the team receives 17 choice problems (one problem per round). For example:

\section{Sample Problem 1}

\section{You need to choose one of the following two projects: \\ Project A Project B}

Your team receives $\mathbf{€ 4 0}$ with probability $\mathbf{1 / 3}$ (each type 1 player receives $€ 10$ and type 2 player receives $€ 20$ )

OR

Your team receives $€ 2.50$ with probability 2/3 (each type 1 player receives $€ 1$ and type 2 player receives $€ \mathbf{0 . 5 0}$ )

Your team receives $€ 7$ with probability 1/3 (each type 1 player receives $€ 3$ and type 2 player receives $€ \mathbf{1}$ )

OR

Your team receives $€ \mathbf{1 6}$ with probability 2/3

(each type 1 player receives $€ 5$ and type 2 player receives $€ \mathbf{6}$ )

Note, that if the project is successful (yields its highest possible payoff), the type 2 player receives higher payoff than any of the type 1 players in the majority of projects.

\footnotetext{
* We provide instructions for the EN treatment.
} 
However, if the project is unsuccessful (yields its lowest possible payoff), the type 2 player receives lower payoff than other players in the majority of projects.

All members of the team irrespective of the type vote on the projects simultaneously, independently and without communicating with each other. These votes form an intermediate decision of the team. The intermediate decision is reached when at least 2 players have voted for the same project (simple majority). After all members of the teams have made their decisions, intermediate decision of the team is reported to the type 2 player (no one else can see the intermediate decision). Type 2 player observes only an intermediate decision. Type 2 player is not informed about the individual decision of each player in the team.

After observing an intermediate decision, the type 2 player can either confirm or alter team's decision. Type 2 player reports the final decision, which is either an intermediate decision or his/her own decision. The team's payoff is calculated based on the final decision, reported by the type 2 player. The final decision of the type 2 player is reported to the entire team. If the type 2 player confirms the intermediate decision, final decision $=$ intermediate decision; if the type 2 player changes the intermediate decision, final decision $=$ his/her own decision.

At the end of Part 3, when decisions on all choice problems are made, the computer program will select one of 17 rounds at random and your payoff from this round only will be paid to you. This problem will reappear on your computer screen. The computer program will simulate projects which were under consideration in selected problem, and your payoff from Part 2 will be displayed.

For example, imagine that the team's intermediate decision (for Problem 1 shown above) has been to choose Project B. However, the type 2 player has decided to change the team decision and has made his/her own decision to select Project A. This means that the final decision of the team is to choose Project A. At the end of Part 3 of the experiment, the computer program will select one problem at random (e.g., Problem 1). Problem 1 will reappear on your screen and the computer program will simulate both project A and project B. Assume that Project A turns out to yield $€ 40$. You will see the team payoff of $€ 40$ and a forgone payoff (the payoff that you could have earned in this round had you chosen another investment project) of $€ 16$ and your individual payoff ( $€ 10$ for each type 1 player and $€ 20$ for the type 2 player) along with your individual forgone payoff ( $€ 5$ for each type $\mathbf{1}$ player and $€ 6$ for the type 2 player) on your screen. You will also be informed on whether the intermediate decision of your team was confirmed or changed by the type 2 player. You will receive your individual payoff and not your team payoff at the end of Part 3 . 


\section{Part 3 (E\&S Procedure)}

Similarly to Part 2, in Part 3 you and other two randomly selected participants will form a team. The composition of your team in Part 3 will be different from the composition of your team in Part 2. During this part of the experiment you will see a decision screen with 11 different situations of the following format:

\begin{tabular}{|cccc}
\multicolumn{5}{c}{ Sample Situation 6} \\
\hline Allocation & A & B & C \\
\hline Person 1 & 19 & 18 & 17 \\
\hline Person 2 & 10 & 10 & 10 \\
\hline Person 3 & 1 & 5 & 9 \\
\hline Total & 30 & 33 & 36 \\
\hline \hline Average 1, 3 & 10 & 11.5 & 13 \\
\hline \hline
\end{tabular}

Each situation refers to a different money allocation (in Euros) among three people: Person 1, Person 2 and Person 3.Your task is to choose allocation A, B or C that you would prefer in case you will be assigned the role of Person 2.

After you have made your choices for all 11 situations, the computer program will randomly assign roles to all team members (i.e., you may be chosen to be Person 1, Person 2 or Person 3). If you are assigned the role of Person 2, your decisions will determine the payoffs for all team members in Part 3. If your role is either Person 1 or Person 3, your decisions will be irrelevant and one of your team-mate's decisions will determine your payoff. After the roles are assigned, the computer program will randomly select one of 11 situations and your payoff (in Euros) will be paid off to you at the end of the experiment according to the column allocation selected by Person 2.

For example, the computer assigned you the role of Person 1 . Then the computer program has randomly selected Situation 6 shown above. Since you have been assigned the role of Person 1 , your payoff depends on the column, chosen by one of your team-mates. Assume that the player, chosen by the computer program to be Person 2, selected column B in Situation 6 . Therefore, you will receive 18 Euros (while Person 2 earns 10 Euros and Person 3 - 5 Euros).

At the end of the experiment, you alone will be informed about your private payoff from Part 1, Part 2 and Part 3. 


\section{Appendix B}

Table 10 Order of Lottery Pairs in the Individual Task of the Experiment

\begin{tabular}{|c|c|c|c|c|c|}
\hline Order & $\begin{array}{l}\text { Lottery } \\
\text { pair ID }\end{array}$ & $\begin{array}{c}\text { Payoff } \\
\text { scheme* }\end{array}$ & Block & Option 1 & Option 2 \\
\hline 1 & 11 & OP & 3 & $1 / 3$ of $€ 8.90,2 / 3$ of $€ 1.50$ & $1 / 3$ of $€ 2.90,2 / 3$ of $€ 3.00$ \\
\hline 2 & 14 & $\mathrm{~L}$ & 4 & $1 / 3$ of $€ 4.50,2 / 3$ of $€ 2.00$ & $1 / 3$ of $€ 3.10,2 / 3$ of $€ 7.20$, \\
\hline 3 & 1 & OP & 1 & $1 / 3$ of $€ 7.90,2 / 3$ of $€ 3.10$ & $1 / 3$ of $€ 3.90,2 / 3$ of $€ 5.10$, \\
\hline 4 & 4 & $\mathrm{~L}$ & 1 & $1 / 3$ of $€ 17.00,2 / 3$ of $€ 0.90$ & $1 / 3$ of $€ 1.20,2 / 3$ of $€ 7.30$ \\
\hline 5 & 10 & OP & 3 & $1 / 3$ of $€ 7.70,2 / 3$ of $€ 3.10$ & $1 / 3$ of $€ 4.30,2 / 3$ of $€ 4.80$, \\
\hline 6 & 13 & $\mathrm{~L}$ & 3 & $1 / 3$ of $€ 10.60,2 / 3$ of $€ 0.60$ & $1 / 3$ of $€ 2.20,2 / 3$ of $€ 9.30$ \\
\hline 7 & 4 & OP & 1 & $1 / 3$ of $€ 9.00,2 / 3$ of $€ 2.00$ & $1 / 3$ of $€ 2.00,2 / 3$ of $€ 5.50$ \\
\hline 8 & 5 & $\mathrm{~L}$ & 1 & $1 / 3$ of $€ 19.00,2 / 3$ of $€ 1.30$ & $1 / 3$ of $€ 1.80,2 / 3$ of $€ 6.90$, \\
\hline 9 & 17 & OP & 4 & $1 / 3$ of $€ 9.20,2 / 3$ of $€ 4.90$ & $1 / 3$ of $€ 2.00,2 / 3$ of $€ 4.00$, \\
\hline 10 & 12 & $\mathrm{~L}$ & 3 & $1 / 3$ of $€ 10.40,2 / 3$ of $€ 0.80$ & $1 / 3$ of $€ 2.80,2 / 3$ of $€ 7.60$ \\
\hline 11 & 6 & OP & 1 & $1 / 3$ of $€ 11.70,2 / 3$ of $€ 1.80$ & $1 / 3$ of $€ 4.30,2 / 3$ of $€ 5.50$, \\
\hline 12 & 7 & $\mathrm{~L}$ & 2 & $1 / 3$ of $€ 9.90,2 / 3$ of $€ 0.50$ & $1 / 3$ of $€ 1.90,2 / 3$ of $€ 4.50$, \\
\hline 13 & 8 & OP & 2 & $1 / 3$ of $€ 4.00,2 / 3$ of $€ 3.00$ & $1 / 3$ of $€ 7.00,2 / 3$ of $€ 4.50$, \\
\hline 14 & 15 & $\mathrm{~L}$ & & $1 / 3$ of $€ 12.00,2 / 3$ of $€ 5.00$ & $1 / 3$ of $€ 3.00,2 / 3$ of $€ 5.00$, \\
\hline 15 & 2 & OP & 1 & $1 / 3$ of $€ 9.70,2 / 3$ of $€ 1.30$ & $1 / 3$ of $€ 3.50,2 / 3$ of $€ 4.40$, \\
\hline 16 & 3 & $\mathrm{~L}$ & 1 & $1 / 3$ of $€ 21.10,2 / 3$ of $€ 1.60$ & $1 / 3$ of $€ 1.90,2 / 3$ of $€ 6.70$, \\
\hline 17 & 16 & OP & 4 & $1 / 3$ of $€ 3.50,2 / 3$ of $€ 2.20$ & $1 / 3$ of $€ 4.10,2 / 3$ of $€ 6.40$, \\
\hline 18 & & HL & & $1 / 10$ of $€ 2.00,9 / 10$ of $€ 1.60$ & $1 / 10$ of $€ 3.85,9 / 10$ of $€ 0.10$ \\
\hline 19 & & HL & & $2 / 10$ of $€ 2.00,8 / 10$ of $€ 1.60$ & $2 / 10$ of $€ 3.85,8 / 10$ of $€ 0.10$ \\
\hline 20 & & HL & & $3 / 10$ of $€ 2.00,7 / 10$ of $€ 1.60$ & $3 / 10$ of $€ 3.85,7 / 10$ of $€ 0.10$ \\
\hline 21 & & HL & & $4 / 10$ of $€ 2.00,6 / 10$ of $€ 1.60$ & $4 / 10$ of $€ 3.85,6 / 10$ of $€ 0.10$ \\
\hline 22 & & $\mathrm{HL}$ & & $5 / 10$ of $€ 2.00,5 / 10$ of $€ 1.60$ & $5 / 10$ of $€ 3.85,5 / 10$ of $€ 0.10$ \\
\hline 23 & & HL & & $6 / 10$ of $€ 2.00,4 / 10$ of $€ 1.60$ & $6 / 10$ of $€ 3.85,4 / 10$ of $€ 0.10$ \\
\hline 24 & & HL & & $7 / 10$ of $€ 2.00,3 / 10$ of $€ 1.60$ & $7 / 10$ of $€ 3.85,3 / 10$ of $€ 0.10$ \\
\hline 25 & & HL & & $8 / 10$ of $€ 2.00,2 / 10$ of $€ 1.60$ & $8 / 10$ of $€ 3.85,2 / 10$ of $€ 0.10$ \\
\hline 26 & & HL & & $9 / 10$ of $€ 2.00,1 / 10$ of $€ 1.60$ & $9 / 10$ of $€ 3.85,1 / 10$ of $€ 0.10$ \\
\hline 27 & & HL & & $10 / 10$ of $€ 2.00,0 / 10$ of $€ 1.60$ & $10 / 10$ of $€ 3.85,0 / 10$ of $€ 0.10$ \\
\hline
\end{tabular}

*Abbreviations: OP - ordinary player; L - leader; HL - Holt and Laury (2002) risk attitude elicitation procedure. 
Table 10 continued

\begin{tabular}{|cccccc|} 
Order & $\begin{array}{c}\text { Lottery } \\
\text { pair ID }\end{array}$ & $\begin{array}{c}\text { Payoff } \\
\text { scheme* }\end{array}$ & Block & $\begin{array}{c}\text { Option } 1 \\
\text { Option } 2\end{array}$ \\
\hline 28 & 8 & L & 2 & $1 / 3$ of $€ 8.00,2 / 3$ of $€ 2.00$ & $1 / 3$ of $€ 2.00,2 / 3$ of $€ 5.00$, \\
\hline 29 & 9 & OP & 2 & $1 / 3$ of $€ 6.60,2 / 3$ of $€ 1.90$ & $1 / 3$ of $€ 4.80,2 / 3$ of $€ 7.30$, \\
\hline 30 & 16 & L & 4 & $1 / 3$ of $€ 3.50,2 / 3$ of $€ 2.20$ & $1 / 3$ of $€ 0.40,2 / 3$ of $€ 1.50$, \\
\hline 31 & 15 & OP & 4 & $1 / 3$ of $€ 4.50,2 / 3$ of $€ 2.00$ & $1 / 3$ of $€ 3.00,2 / 3$ of $€ 5.00$, \\
\hline 32 & 6 & L & 1 & $1 / 3$ of $€ 23.70,2 / 3$ of $€ 0.90$ & $1 / 3$ of $€ 1.90,2 / 3$ of $€ 7.30$, \\
\hline 33 & 5 & OP & 1 & $1 / 3$ of $€ 8.70,2 / 3$ of $€ 2.70$ & $1 / 3$ of $€ 3.90,2 / 3$ of $€ 5.10$, \\
\hline 34 & 9 & L & 2 & $1 / 3$ of $€ 15.80,2 / 3$ of $€ 1.40$ & $1 / 3$ of $€ 1.80,2 / 3$ of $€ 8.40$, \\
\hline 35 & 7 & OP & 2 & $1 / 3$ of $€ 7.90,2 / 3$ of $€ 2.00$ & $1 / 3$ of $€ 2.90,2 / 3$ of $€ 3.00$, \\
\hline 36 & 11 & L & 3 & $1 / 3$ of $€ 10.00,2 / 3$ of $€ 0.70$ & $1 / 3$ of $€ 2.00,2 / 3$ of $€ 6.20$, \\
\hline 37 & 13 & OP & 3 & $1 / 3$ of $€ 10.20,2 / 3$ of $€ 4.90$ & $1 / 3$ of $€ 3.00,2 / 3$ of $€ 4.00$, \\
\hline 38 & 10 & L & 3 & $1 / 3$ of $€ 8.90,2 / 3$ of $€ 2.50$ & $1 / 3$ of $€ 2.10,2 / 3$ of $€ 5.90$, \\
\hline 39 & 3 & OP & 1 & $1 / 3$ of $€ 9.00,2 / 3$ of $€ 3.60$ & $1 / 3$ of $€ 4.80,2 / 3$ of $€ 5.70$, \\
\hline 40 & 2 & L & 1 & $1 / 3$ of $€ 18.80,2 / 3$ of $€ 0.50$ & $1 / 3$ of $€ 2.20,2 / 3$ of $€ 5.80$, \\
\hline 41 & 14 & OP & 4 & $1 / 3$ of $€ 4.50,2 / 3$ of $€ 2.00$ & $1 / 3$ of $€ 0.60,2 / 3$ of $€ 1.70$, \\
\hline 42 & 17 & L & 4 & $1 / 3$ of $€ 2.50,2 / 3$ of $€ 1.50$ & $1 / 3$ of $€ 2.00,2 / 3$ of $€ 4.00$, \\
\hline 43 & 12 & OP & 3 & $1 / 3$ of $€ 10.10,2 / 3$ of $€ 2.90$ & $1 / 3$ of $€ 3.10,2 / 3$ of $€ 3.40$, \\
\hline 44 & 1 & L & 1 & $1 / 3$ of $€ 14.50,2 / 3$ of $€ 1.00$ & $1 / 3$ of $€ 1.50,2 / 3$ of $€ 6.00$, \\
\hline
\end{tabular}

*Abbreviations: OP - ordinary player; L - leader; HL - Holt and Laury (2002) risk attitude elicitation procedure. 


\section{Appendix C}

\section{Table 11 Order of Lottery Pairs in the Team Task of the Experiment*}

\begin{tabular}{|c|c|c|c|c|}
\hline Order & $\begin{array}{l}\text { Lottery } \\
\text { pair ID }\end{array}$ & Block & Project A & Project B \\
\hline 1 & 7 & 2 & $\begin{array}{l}\text { Your team receives } € 25.70 \text { with } \\
\text { probability } 1 / 3 \text { (each type } 1 \text { player } \\
\text { receives } € 7.90 \text { and type } 2 \text { player } \\
\text { receives } € 9.90 \text { ) } \\
\text { OR } \\
\text { Your team receives } € 4.50 \text { with } \\
\text { probability } 2 / 3 \text { (each type } 1 \text { player } \\
\text { receives €2 and type } 2 \text { player receives } \\
€ 0.50 \text { ) }\end{array}$ & $\begin{array}{l}\text { Your team receives } € 10.50 \text { with } \\
\text { probability } 2 / 3 \text { (each type } 1 \text { player } \\
\text { receives } € 3 \text { and type } 2 \text { player receives } \\
€ 4.50 \text { ) } \\
\text { OR } \\
\text { Your team receives } € 7.70 \text { with } \\
\text { probability } 1 / 3 \text { (each type } 1 \text { player } \\
\text { receives } € 2.90 \text { and type } 2 \text { player receives } \\
€ 1.90\end{array}$ \\
\hline 2 & 4 & 1 & $\begin{array}{l}\text { Your team receives } € 35 \text { with } \\
\text { probability } 1 / 3 \text { (each type } 1 \text { player } \\
\text { receives } € 9 \text { and type } 2 \text { player receives } \\
€ 17 \text { ) } \\
\text { OR } \\
\text { Your team receives } € 4.90 \text { with } \\
\text { probability } 2 / 3 \text { (each type } 1 \text { player } \\
\text { receives } € 2 \text { and type } 2 \text { player receives } \\
€ 0.90)\end{array}$ & $\begin{array}{l}\text { Your team receives } € 18.30 \text { with } \\
\text { probability } 2 / 3 \text { (each type } 1 \text { player } \\
\text { receives } € 5.50 \text { and type } 2 \text { player receives } \\
€ 7.30 \text { ) } \\
\text { OR } \\
\text { Your team receives } € 5.20 \text { with } \\
\text { probability } 1 / 3 \text { (each type } 1 \text { player } \\
\text { receives } € 2 \text { and type } 2 \text { player receives } \\
€ 1.20 \text { ) }\end{array}$ \\
\hline 3 & 6 & 1 & $\begin{array}{l}\text { Your team receives } € 47.1 \text { with } \\
\text { probability } 1 / 3 \text { (each type } 1 \text { player } \\
\text { receives } € 11.7 \text { and type } 2 \text { player } \\
\text { receives } € 23.7 \text { ) } \\
\text { OR } \\
\text { Your team receives } € 4.50 \text { with } \\
\text { probability } 2 / 3 \text { (each type } 1 \text { player } \\
\text { receives } € 1.80 \text { and type } 2 \text { player } \\
\text { receives } € 0.90 \text { ) }\end{array}$ & $\begin{array}{l}\text { Your team receives } € 18.30 \text { with } \\
\text { probability } 2 / 3 \text { (each type } 1 \text { player } \\
\text { receives } € 5.50 \text { and type } 2 \text { player receives } \\
€ 7.30 \text { ) } \\
\text { OR } \\
\text { Your team receives } € 10.50 \text { with } \\
\text { probability } 1 / 3 \text { (each type } 1 \text { player } \\
\text { receives } € 4.30 \text { and type } 2 \text { player receives } \\
€ 1.90)\end{array}$ \\
\hline 4 & 3 & 1 & $\begin{array}{l}\text { Your team receives } € 39.10 \text { with } \\
\text { probability } 1 / 3 \text { (each type } 1 \text { player } \\
\text { receives } € 9 \text { and type } 2 \text { player receives } \\
€ 21.10 \text { ) } \\
\text { OR } \\
\text { Your team receives } € 8.80 \text { with } \\
\text { probability } 2 / 3 \text { (each type } 1 \text { player } \\
\text { receives } € 3.60 \text { and type } 2 \text { player } \\
\text { receives } € 1.60 \text { ) }\end{array}$ & $\begin{array}{l}\text { Your team receives } € 18.10 \text { with } \\
\text { probability } 2 / 3 \text { (each type } 1 \text { player } \\
\text { receives } € 5.70 \text { and type } 2 \text { player receives } \\
€ 6.70 \text { ) } \\
\text { OR } \\
\text { Your team receives } € 11.50 \text { with } \\
\text { probability } 1 / 3 \text { (each type } 1 \text { player } \\
\text { receives } € 4.80 \text { and type } 2 \text { player receives } \\
€ 1.90)\end{array}$ \\
\hline
\end{tabular}

* Type 1 player refers to “ordinary player”, type 2 player refers to "leader”. 
Table 11 continued*

\begin{tabular}{|c|c|c|c|c|}
\hline Order & $\begin{array}{l}\text { Lottery } \\
\text { pair ID }\end{array}$ & Block & Project A & Project B \\
\hline 5 & 9 & 2 & $\begin{array}{l}\text { Your team receives } € 29 \text { with } \\
\text { probability } 1 / 3 \text { (each type } 1 \text { player } \\
\text { receives } € 6.60 \text { and type } 2 \text { player } \\
\text { receives } € 15.80 \text { ) } \\
\text { OR } \\
\text { Your team receives } € 5.20 \text { with } \\
\text { probability } 2 / 3 \text { (each type } 1 \text { player } \\
\text { receives } € 1.90 \text { and type } 2 \text { player } \\
\text { receives } € 1.40 \text { ) }\end{array}$ & $\begin{array}{l}\text { Your team receives } € 23 \text { with } \\
\text { probability } 2 / 3 \text { (each type } 1 \text { player } \\
\text { receives } € 7.30 \text { and type } 2 \text { player } \\
\text { receives } € 8.40 \text { ) } \\
\text { OR } \\
\text { Your team receives } € 11.40 \text { with } \\
\text { probability } 1 / 3 \text { (each type } 1 \text { player } \\
\text { receives } € 4.80 \text { and type } 2 \text { player } \\
\text { receives } € 1.80 \text { ) }\end{array}$ \\
\hline 6 & 13 & 3 & $\begin{array}{l}\text { Your team receives } € 31 \text { with } \\
\text { probability } 1 / 3 \text { (each type } 1 \text { player } \\
\text { receives } € 10.20 \text { and type } 2 \text { player } \\
\text { receives } € 10.60 \text { ) } \\
\text { OR } \\
\text { Your team receives } € 10.40 \text { with } \\
\text { probability } 2 / 3 \text { (each type } 1 \text { player } \\
\text { receives } € 4.90 \text { and type } 2 \text { player } \\
\text { receives } € 0.60 \text { ) }\end{array}$ & $\begin{array}{l}\text { Your team receives } € 17.30 \text { with } \\
\text { probability } 2 / 3 \text { (each type } 1 \text { player } \\
\text { receives } € 4 \text { and type } 2 \text { player receives } \\
€ 9.30 \text { ) } \\
\text { Your team receives } € 8.20 \text { with } \\
\text { probability } 1 / 3 \text { (each type } 1 \text { player } \\
\text { receives } € 3 \text { and type } 2 \text { player receives } \\
€ 2.20 \text { ) }\end{array}$ \\
\hline 7 & 12 & 3 & $\begin{array}{l}\text { Your team receives } € 30.60 \text { with } \\
\text { probability } 1 / 3 \text { (each type } 1 \text { player } \\
\text { receives } € 10.10 \text { and type } 2 \text { player } \\
\text { receives } € 10.40 \text { ) } \\
\text { OR } \\
\text { Your team receives } € 6.60 \text { with } \\
\text { probability } 2 / 3 \text { (each type } 1 \text { player } \\
\text { receives } € 2.90 \text { and type } 2 \text { player } \\
\text { receives } € 0.80 \text { ) }\end{array}$ & $\begin{array}{l}\text { Your team receives } € 14.40 \text { with } \\
\text { probability } 2 / 3 \text { (each type } 1 \text { player } \\
\text { receives } € 3.40 \text { and type } 2 \text { player } \\
\text { receives } € 7.60 \text { ) }\end{array}$ \\
\hline 8 & 8 & 2 & $\begin{array}{l}\text { Your team receives } € 16 \text { with } \\
\text { probability } 1 / 3 \text { (each type } 1 \text { player } \\
\text { receives } € 4 \text { and type } 2 \text { player receives } \\
€ 8 \text { ) } \\
\text { Your team receives } € 8 \text { with } \\
\text { probability } 2 / 3 \text { (each type } 1 \text { player } \\
\text { receives } € 3 \text { and type } 2 \text { player receives } \\
€ 2 \text { ) }\end{array}$ & $\begin{array}{l}\text { Your team receives } € 14 \text { with } \\
\text { probability } 2 / 3 \text { (each type } 1 \text { player } \\
\text { receives } € 4.50 \text { and type } 2 \text { player } \\
\text { receives } € 5 \text { ) } \\
\text { OR } \\
\text { Your team receives } € 16 \text { with } \\
\text { probability } 1 / 3 \text { (each type } 1 \text { player } \\
\text { receives } € 7 \text { and type } 2 \text { player receives } \\
€ 2 \text { ) }\end{array}$ \\
\hline
\end{tabular}

* Type 1 player refers to “ordinary player”, type 2 player refers to "leader”. 
Table 11 continued*

\begin{tabular}{|c|c|c|c|c|}
\hline Order & $\begin{array}{l}\text { Lottery } \\
\text { pair ID }\end{array}$ & Block & Project A & Project B \\
\hline 9 & 10 & 3 & $\begin{array}{l}\text { Your team receives } € 24.30 \text { with } \\
\text { probability } 1 / 3 \text { (each type } 1 \text { player } \\
\text { receives } € 7.70 \text { and type } 2 \text { player } \\
\text { receives } € 8.90 \text { ) } \\
\text { OR } \\
\text { Your team receives } € 8.70 \text { with } \\
\text { probability } 2 / 3 \text { (each type } 1 \text { player } \\
\text { receives } € 3.10 \text { and type } 2 \text { player } \\
\text { receives } € 2.50 \text { ) }\end{array}$ & $\begin{array}{l}\text { Your team receives } € 15.50 \text { with } \\
\text { probability } 2 / 3 \text { (each type } 1 \text { player } \\
\text { receives } € 4.80 \text { and type } 2 \text { player } \\
\text { receives } € 5.90 \text { ) } \\
\text { OR } \\
\text { Your team receives } € 10.70 \text { with } \\
\text { probability } 1 / 3 \text { (each type } 1 \text { player } \\
\text { receives } € 4.30 \text { and type } 2 \text { player } \\
\text { receives } € 2.10 \text { ) }\end{array}$ \\
\hline 10 & 2 & 1 & $\begin{array}{l}\text { Your team receives } € 38.20 \text { with } \\
\text { probability } 1 / 3 \text { (each type } 1 \text { player } \\
\text { receives } € 9.70 \text { and type } 2 \text { player } \\
\text { receives } € 18.80 \text { ) } \\
\text { OR } \\
\text { Your team receives } € 3.10 \text { with } \\
\text { probability } 2 / 3 \text { (each type } 1 \text { player } \\
\text { receives } € 1.30 \text { and type } 2 \text { player } \\
\text { receives } € 0.50 \text { ) }\end{array}$ & $\begin{array}{l}\text { Your team receives } € 14.60 \text { with } \\
\text { probability } 2 / 3 \text { (each type } 1 \text { player } \\
\text { receives } € 4.40 \text { and type } 2 \text { player } \\
\text { receives } € 5.80 \text { ) } \\
\text { OR } \\
\text { Your team receives } € 9.20 \text { with } \\
\text { probability } 1 / 3 \text { (each type } 1 \text { player } \\
\text { receives } € 3.50 \text { and type } 2 \text { player } \\
\text { receives } € 2.20 \text { ) }\end{array}$ \\
\hline 11 & 17 & 4 & $\begin{array}{l}\text { Your team receives } € 20.90 \text { with } \\
\text { probability } 1 / 3 \text { (each type } 1 \text { player } \\
\text { receives } € 9.20 \text { and type } 2 \text { player } \\
\text { receives } € 2.50 \text { ) } \\
\text { OR } \\
\text { Your team receives } € 11.30 \text { with } \\
\text { probability } 2 / 3 \text { (each type } 1 \text { player } \\
\text { receives } € 4.90 \text { and type } 2 \text { player } \\
\text { receives } € 1.50 \text { ) }\end{array}$ & $\begin{array}{l}\text { Your team receives } € 12 \text { with } \\
\text { probability } 2 / 3 \text { (each type } 1 \text { player } \\
\text { receives } € 4 \text { and type } 2 \text { player } \\
\text { receives } € 4 \text { ) } \\
\begin{array}{l}\text { OR } \\
\text { Your team receives } € 6\end{array} \text { with } \\
\begin{array}{l}\text { probability } 1 / 3 \text { (each type } 1 \text { player } \\
\text { receives } € 2 \text { and type } 2 \text { player } \\
\text { receives } € 2 \text { ) }\end{array}\end{array}$ \\
\hline 12 & 15 & 4 & $\begin{array}{l}\text { Your team receives } € 21 \text { with } \\
\text { probability } 1 / 3 \text { (each type } 1 \text { player } \\
\text { receives } € 4.50 \text { and type } 2 \text { player } \\
\text { receives } € 12 \text { ) } \\
\text { OR } \\
\text { Your team receives } € 9 \text { with } \\
\text { probability } 2 / 3 \text { (each type } 1 \text { player } \\
\text { receives } € 2 \text { and type } 2 \text { player } \\
\text { receives } € 5 \text { ) }\end{array}$ & $\begin{array}{l}\text { Your team receives } € 15 \text { with } \\
\text { probability } 2 / 3 \text { (each type } 1 \text { player } \\
\text { receives } € 5 \text { and type } 2 \text { player } \\
\text { receives } € 5 \text { ) } \\
\text { OR } \\
\text { Your team receives } € 9 \text { with } \\
\text { probability } 1 / 3 \text { (each type } 1 \text { player } \\
\text { receives } € 3 \text { and type } 2 \text { player } \\
\text { receives } € 3 \text { ) }\end{array}$ \\
\hline
\end{tabular}

* Type 1 player refers to “ordinary player”, type 2 player refers to "leader”. 
Table 11 continued*

\begin{tabular}{|c|c|c|c|c|}
\hline Order & $\begin{array}{l}\text { Lottery } \\
\text { pair ID }\end{array}$ & Block & Project A & Project B \\
\hline 13 & 11 & 3 & $\begin{array}{l}\text { Your team receives } € 27.80 \text { with } \\
\text { probability } 1 / 3 \text { (each type } 1 \text { player } \\
\text { receives } € 8.90 \text { and type } 2 \text { player } \\
\text { receives } € 10 \text { ) } \\
\text { OR } \\
\text { Your team receives } € 3.70 \text { with } \\
\text { probability } 2 / 3 \text { (each type } 1 \text { player } \\
\text { receives } € 1.50 \text { and type } 2 \text { player } \\
\text { receives } € 0.70 \text { ) }\end{array}$ & $\begin{array}{l}\text { Your team receives } € 12.20 \text { with } \\
\text { probability 2/3 (each type } 1 \text { player } \\
\text { receives } € 3 \text { and type } 2 \text { player receives } \\
€ 6.20 \text { ) } \\
\text { Your team receives } € 7.80 \text { with } \\
\text { probability } 1 / 3 \text { (each type } 1 \text { player } \\
\text { receives } € 2.90 \text { and type } 2 \text { player receives } \\
€ 2 \text { ) }\end{array}$ \\
\hline 14 & 5 & 1 & $\begin{array}{l}\text { Your team receives } € 36.40 \text { with } \\
\text { probability } 1 / 3 \text { (each type } 1 \text { player } \\
\text { receives } € 8.70 \text { and type } 2 \text { player } \\
\text { receives } € 19 \text { ) } \\
\text { OR } \\
\text { Your team receives } € 6.70 \text { with } \\
\text { probability } 2 / 3 \text { (each type } 1 \text { player } \\
\text { receives } € 2.70 \text { and type } 2 \text { player } \\
\text { receives } € 1.30 \text { ) }\end{array}$ & $\begin{array}{l}\text { Your team receives } € 17.10 \text { with } \\
\text { probability } 2 / 3 \text { (each type } 1 \text { player } \\
\text { receives } € 5.10 \text { and type } 2 \text { player receives } \\
€ 6.90 \text { ) } \\
\text { Your team receives } € 9.60 \text { with } \\
\text { probability } 1 / 3 \text { (each type } 1 \text { player } \\
\text { receives } € 3.90 \text { and type } 2 \text { player receives } \\
€ 1.80 \text { ) }\end{array}$ \\
\hline 15 & 14 & 4 & $\begin{array}{l}\text { Your team receives } € 13.50 \text { with } \\
\text { probability } 1 / 3 \text { (each type } 1 \text { player } \\
\text { receives } € 4.50 \text { and type } 2 \text { player } \\
\text { receives } € 4.50 \text { ) } \\
\text { OR } \\
\text { Your team receives } € 6 \text { with } \\
\text { probability } 2 / 3 \text { (each type } 1 \text { player } \\
\text { receives } € 2 \text { and type } 2 \text { player receives } \\
€ 2 \text { ) }\end{array}$ & $\begin{array}{l}\text { Your team receives } € 10.60 \text { with } \\
\text { probability } 2 / 3 \text { (each type } 1 \text { player } \\
\text { receives } € 1.70 \text { and type } 2 \text { player receives } \\
€ 7.20 \text { ) } \\
\text { OR } \\
\text { Your team receives } € 4.30 \text { with } \\
\text { probability } 1 / 3 \text { (each type } 1 \text { player } \\
\text { receives } € 0.60 \text { and type } 2 \text { player receives } \\
€ 3.10 \text { ) }\end{array}$ \\
\hline 16 & 1 & 1 & $\begin{array}{l}\text { Your team receives } € 30.30 \text { with } \\
\text { probability } 1 / 3 \text { (each type } 1 \text { player } \\
\text { receives } € 7.90 \text { and type } 2 \text { player } \\
\text { receives } € 14.50 \text { ) } \\
\text { OR } \\
\text { Your team receives } € 7.20 \text { with } \\
\text { probability } 2 / 3 \text { (each type } 1 \text { player } \\
\text { receives } € 3.10 \text { and type } 2 \text { player } \\
\text { receives } € 1 \text { ) }\end{array}$ & 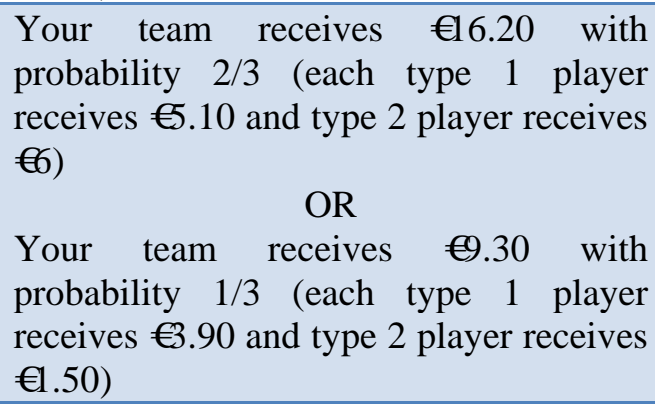 \\
\hline 17 & 16 & 4 & $\begin{array}{l}\text { Your team receives } € 10.50 \text { with } \\
\text { probability } 1 / 3 \text { (each type } 1 \text { player } \\
\text { receives } € 3.50 \text { and type } 2 \text { player } \\
\text { receives } € 3.50 \text { ) } \\
\text { OR } \\
\text { Your team receives } € 6.60 \text { with } \\
\text { probability } 2 / 3 \text { (each type } 1 \text { player } \\
\text { receives } € 2.20 \text { and type } 2 \text { player } \\
\text { receives } € 2.20 \text { ) }\end{array}$ & $\begin{array}{l}\text { Your team receives } € 14.30 \text { with } \\
\text { probability } 2 / 3 \text { (each type } 1 \text { player } \\
\text { receives } € 6.40 \text { and type } 2 \text { player receives } \\
€ 1.50 \text { ) } \\
\text { OR } \\
\text { Your team receives } € 8.60 \text { with } \\
\text { probability } 1 / 3 \text { (each type } 1 \text { player } \\
\text { receives } € 4.10 \text { and type } 2 \text { player receives } \\
€ 0.40 \text { ) }\end{array}$ \\
\hline
\end{tabular}

* Type 1 player refers to "ordinary player”, type 2 player refers to "leader”. 


\section{APPENDiX D}

\section{Results of the E\&S Procedure}

We find that the majority of participants (85.0\%) choose allocations, consistent with EF, $\mathrm{F} \& S$ and MM preferences in the F and Fx situations. In the E treatment, slightly higher number of participants (47.8\%) opt for the allocation, consistent with F\&S and MM preferences and in the Ex treatment slightly higher number of participants (48.9\%) choose allocation consistent with EF and ERC preferences. ${ }^{39}$ In Envy games, the majority of participants select allocation, consistent with EF and MM concerns in N, Ny and Nyi situations (between 77.2\% and 90.3\%) and with EF, ERC and MM preferences in Nx situation (93.9\%). In Rich and Poor games slight majority of participants (52.8\%) opt for allocation consistent with EF preferences in the Ey situation and a slightly larger number of participants (45.6\%) choose allocation consistent with $\mathrm{EF}$ and $\mathrm{MM}$ preferences in the $\mathrm{P}$ situation. In the $\mathrm{R}$ situation a larger number of participants (44.4\%) choose allocation, consistent with EF, ERC and F\&S preferences. ${ }^{40}$

The data suggest that ordinary players and leaders exhibit similar behavior in all clusters of E\&S situations. Except for situations $\mathrm{Nx}$ and $\mathrm{Ny}$ we could not reject a null hypothesis that leaders' and ordinary players' choices are not statistically significantly different. ${ }^{41}$ Nonparametric comparison indicates that ordinary players choose allocation A in the Nx situation more often than leaders. Leaders choose allocation $\mathrm{C}$ more often than ordinary players in the $\mathrm{Nx}$ situation. ${ }^{42}$ In the Ny situation leaders opt for allocation A more often than ordinary players and ordinary players choose allocation B more often than leaders. We also do not find statistically significant differences in the behavior of leaders across treatments.

\footnotetext{
${ }^{39}$ This result appears to be at odds with Engelmann and Strobel (2004) who find that all three allocations are chosen with the same probability.

${ }^{40}$ This result in not consistent with the results reported in Engelmann and Strobel (2004), where a slight majority of participants (53.3\%) opt for allocation, consistent with MM concerns.

${ }^{41}$ Test results are available from the authors upon request.

${ }^{42}$ In this case, however, statistical test cannot not be conducted because none of the ordinary players have chosen allocation C.
} 
Table 12 [A] Results of the E\&S Procedure: Taxation Games

\begin{tabular}{|c|c|c|c|c|c|c|c|c|c|c|c|c|}
\hline \multirow[b]{3}{*}{ Allocation } & \multicolumn{12}{|c|}{ Situation } \\
\hline & \multicolumn{3}{|c|}{$\mathbf{F}$} & \multicolumn{3}{|c|}{$\mathbf{E}$} & \multicolumn{3}{|c|}{$\mathbf{F x}$} & \multicolumn{3}{|c|}{ Ex } \\
\hline & A & B & C & A & B & C & A & B & C & A & B & C \\
\hline Person 1 & 8.2 & 8.8 & 9.4 & 9.4 & 8.4 & 7.4 & 17 & 18 & 19 & 21 & 17 & 13 \\
\hline Person 2 & 5.6 & 5.6 & 5.6 & 6.4 & 6.4 & 6.4 & 10 & 10 & 10 & 12 & 12 & 12 \\
\hline Person 3 & 4.6 & 3.6 & 2.6 & 2.6 & 3.2 & 3.8 & 9 & 5 & 1 & 3 & 4 & 5 \\
\hline Total & 18.4 & 18 & 17.6 & 18.4 & 18.0 & 17.6 & 36 & 33 & 30 & 36 & 33 & 30 \\
\hline Average & 6.4 & 6.2 & 6.0 & 6.0 & 5.8 & 5.6 & 13 & 11.5 & 10 & 12 & 10.5 & 9 \\
\hline Relative 2 & 0.304 & 0.311 & 0.318 & 0.348 & 0.356 & 0.364 & 0.278 & 0.303 & 0.333 & 0.333 & 0.364 & 0.400 \\
\hline \multicolumn{13}{|l|}{ Prediction } \\
\hline EF & A & & & A & & & A & & & A & & \\
\hline ERC & & & C & A & & & & & C & A & & \\
\hline F\&S & A & & & & & C & A & & & & & C \\
\hline MM & A & & & & & C & A & & & & & C \\
\hline \multicolumn{13}{|c|}{ Percentage of choices } \\
\hline $\begin{array}{l}\text { Ordinary } \\
\text { players: }\end{array}$ & 85.8 & 10.0 & 4.2 & 28.3 & 23.3 & 48.3 & 85.0 & 10.0 & 5.0 & 50.8 & 20.0 & 29.2 \\
\hline$E X$ treatment & 81.3 & 12.5 & 6.3 & 33.3 & 18.8 & 47.9 & 81.3 & 14.6 & 4.2 & 54.2 & 20.8 & 25.0 \\
\hline EN treatment & 88.9 & 8.3 & 2.8 & 25.0 & 26.4 & 48.6 & 87.5 & 6.9 & 5.6 & 48.6 & 19.4 & 31.9 \\
\hline Leaders: & 83.3 & 10.0 & 6.7 & 36.7 & 16.7 & 46.7 & 85.0 & 6.7 & 8.3 & 45.0 & 16.7 & 38.3 \\
\hline$E X$ treatment & 95.8 & 4.2 & 0.0 & 20.8 & 12.5 & 66.7 & 95.8 & 4.2 & 0.0 & 33.3 & 20.8 & 45.8 \\
\hline$E N$ treatment & 75.0 & 13.9 & 11.1 & 47.2 & 19.4 & 33.3 & 77.8 & 8.3 & 13.9 & 52.8 & 13.9 & 33.3 \\
\hline All: & 85.0 & 10.0 & 5.0 & 31.1 & 21.1 & 47.8 & 85.0 & 8.9 & 6.1 & 48.9 & 18.9 & 32.2 \\
\hline$E X$ treatment & 86.1 & 9.7 & 4.2 & 29.2 & 16.7 & 54.2 & 86.1 & 11.1 & 2.8 & 47.2 & 20.8 & 31.9 \\
\hline$E N$ treatment & 84.3 & 10.2 & 5.6 & 32.4 & 24.1 & 43.5 & 84.3 & 7.4 & 8.3 & 50.0 & 17.6 & 32.4 \\
\hline $\begin{array}{l}\text { Engelmann } \\
\text { and } \\
\text { Strobel (2004) } \\
\text { results: }\end{array}$ & 83.8 & 10.3 & 5.9 & 39.7 & 23.5 & 36.7 & 86.7 & 6.7 & 6.7 & 40.0 & 16.7 & 43.3 \\
\hline
\end{tabular}


Table 12 [B] Results of the E\&S Procedure: Envy Games

\begin{tabular}{|c|c|c|c|c|c|c|c|c|c|c|c|c|}
\hline \multirow[b]{3}{*}{ Allocation } & \multicolumn{12}{|c|}{ Situation } \\
\hline & \multicolumn{3}{|c|}{$\mathbf{N}$} & \multicolumn{3}{|c|}{$\mathbf{N x}$} & \multicolumn{3}{|c|}{ Ny } & \multicolumn{3}{|c|}{ Nyi } \\
\hline & $\mathbf{A}$ & B & C & A & B & C & A & B & C & A & B & C \\
\hline Person 1 & 16.0 & 13.0 & 10.0 & 16.0 & 13.0 & 10.0 & 16.0 & 13.0 & 10.0 & 16.0 & 13.0 & 10.0 \\
\hline Person 2 & 8.0 & 8.0 & 8.0 & 9.0 & 8.0 & 7.0 & 7.0 & 8.0 & 9.0 & 7.5 & 8.0 & 8.5 \\
\hline Person 3 & 5.0 & 3.0 & 1.0 & 5.0 & 3.0 & 1.0 & 5.0 & 3.0 & 1.0 & 5.0 & 3.0 & 1.0 \\
\hline Total & 29.0 & 24.0 & 19.0 & 30.0 & 24.0 & 18.0 & 28.0 & 24.0 & 20.0 & 28.5 & 24.0 & 19.5 \\
\hline Average & 10.5 & 8.0 & 5.5 & 10.5 & 8.0 & 5.5 & 10.5 & 8.0 & 5.5 & 10.5 & 8.0 & 5.5 \\
\hline Relative 2 & 0.276 & 0.333 & 0.421 & 0.300 & 0.333 & 0.389 & 0.250 & 0.333 & 0.450 & 0.263 & 0.333 & 0.436 \\
\hline \multicolumn{13}{|l|}{ Prediction } \\
\hline EF & A & & & A & & & A & & & A & & \\
\hline ERC & & B & & A & B & & & B & C & & B & $\mathrm{C}$ \\
\hline F\&S & & & C & & & C & & & C & & & C \\
\hline MM & A & & & A & & & A & & & A & & \\
\hline \multicolumn{13}{|c|}{ Percentage of choices } \\
\hline $\begin{array}{l}\text { Ordinary } \\
\text { players: }\end{array}$ & 90.8 & 5.8 & 3.3 & 96.7 & 3.3 & 0.0 & 74.2 & 14.2 & 11.7 & 75.0 & 11.7 & 13.3 \\
\hline$E X$ treatment & 85.4 & 8.3 & 6.3 & 97.9 & 2.1 & 0.0 & 66.7 & 16.7 & 16.7 & 66.7 & 12.5 & 20.8 \\
\hline EN treatment & 94.4 & 4.2 & 1.4 & 95.8 & 4.2 & 0.0 & 79.2 & 12.5 & 8.3 & 80.6 & 11.1 & 8.3 \\
\hline Leaders: & 91.7 & 5.0 & 3.3 & 88.3 & 3.3 & 8.3 & 88.3 & 1.7 & 10.0 & 81.7 & 8.3 & 10.0 \\
\hline$E X$ treatment & 100 & 0.0 & 0.0 & 95.8 & 0.0 & 4.2 & 95.8 & 0.0 & 4.2 & 87.5 & 8.3 & 4.2 \\
\hline EN treatment & 86.1 & 8.3 & 5.6 & 83.3 & 5.6 & 11.1 & 83.3 & 2.8 & 13.9 & 77.8 & 8.3 & 13.9 \\
\hline All: & 91.1 & 5.6 & 3.3 & 93.9 & 3.3 & 2.8 & 78.9 & 10.0 & 11.1 & 77.2 & 10.6 & 12.2 \\
\hline$E X$ treatment & 90.3 & 5.6 & 4.2 & 97.2 & 1.4 & 1.4 & 76.4 & 11.1 & 12.5 & 73.6 & 11.1 & 15.3 \\
\hline EN treatment & 91.7 & 5.6 & 2.8 & 91.7 & 4.6 & 3.7 & 80.6 & 9.3 & 10.2 & 79.6 & 10.2 & 10.2 \\
\hline $\begin{array}{l}\text { Engelmann and } \\
\text { Strobel (2004) } \\
\underline{\text { results: }}\end{array}$ & 70.0 & 26.7 & 3.3 & 83.3 & 13.3 & 3.3 & 76.7 & 13.3 & 10.0 & 60.0 & 16.7 & 23.3 \\
\hline
\end{tabular}


Table 12 [C] Results of the E\&S Procedure: Rich and Poor Games

\begin{tabular}{|c|c|c|c|c|c|c|c|c|c|}
\hline \multirow[b]{3}{*}{ Allocation } & \multicolumn{9}{|c|}{ Situation } \\
\hline & \multicolumn{3}{|c|}{$\mathbf{R}$} & \multicolumn{3}{|c|}{$\mathbf{P}$} & \multicolumn{3}{|c|}{ Ey } \\
\hline & A & B & C & A & B & C & A & B & C \\
\hline Person 1 & 11.0 & 8.0 & 5.0 & 14.0 & 11.0 & 8.0 & 21.0 & 17.0 & 13.0 \\
\hline Person 2 & 12.0 & 12.0 & 12.0 & 4.0 & 4.0 & 4.0 & 9.0 & 9.0 & 9.0 \\
\hline Person 3 & 2.0 & 3.0 & 4.0 & 5.0 & 6.0 & 7.0 & 3.0 & 4.0 & 5.0 \\
\hline Total & 25.0 & 23.0 & 21.0 & 23.0 & 21.0 & 19.0 & 33.0 & 30.0 & 27.0 \\
\hline Average & 6.5 & 5.5 & 4.5 & 9.5 & 8.5 & 7.5 & 12 & 10.5 & 9.0 \\
\hline Relative 2 & 0.480 & 0.522 & 0.571 & 0.174 & 0.190 & 0.211 & 0.273 & 0.300 & 0.333 \\
\hline \multicolumn{10}{|l|}{ Prediction } \\
\hline EF & A & & & A & & & A & & \\
\hline ERC & A & & & & & C & & & C \\
\hline F\&S & A & & & & & C & & & C \\
\hline MM & & & C & A & B & C & & & C \\
\hline \multicolumn{10}{|l|}{ Percentage of choices } \\
\hline Ordinary players: & 41.7 & 32.5 & 25.8 & 44.2 & 32.5 & 23.3 & 50.0 & 14.2 & 35.8 \\
\hline$E X$ treatment & 45.8 & 35.4 & 18.8 & 47.9 & 31.3 & 20.8 & 58.3 & 20.8 & 20.8 \\
\hline EN treatment & 38.9 & 30.6 & 30.6 & 41.7 & 33.3 & 25.0 & 44.4 & 9.7 & 45.8 \\
\hline Leaders: & 50.0 & 25.0 & 25.0 & 48.3 & 21.7 & 30.0 & 58.3 & 20.0 & 21.7 \\
\hline$E X$ treatment & 37.5 & 41.7 & 20.8 & 33.3 & 29.2 & 37.5 & 45.8 & 29.2 & 25.0 \\
\hline$E N$ treatment & 58.3 & 13.9 & 27.8 & 58.3 & 16.7 & 25.0 & 66.7 & 13.9 & 19.4 \\
\hline All: & 44.4 & 30.0 & 25.6 & 45.6 & 28.9 & 25.6 & 52.8 & 16.1 & 31.1 \\
\hline$E X$ treatment & 43.1 & 37.5 & 19.4 & 43.1 & 30.6 & 26.4 & 54.2 & 23.6 & 22.2 \\
\hline EN treatment & 45.4 & 25.0 & 29.6 & 47.2 & 27.8 & 25.0 & 51.9 & 11.1 & 37.0 \\
\hline $\begin{array}{l}\text { Engelmann and } \\
\text { Strobel (2004) results: }\end{array}$ & 26.7 & 20.0 & 53.3 & 60.0 & 6.7 & 33.3 & 40.0 & 23.3 & 36.7 \\
\hline
\end{tabular}




\section{Appendix E}

\section{Machiavellian Scale Questionnaire}

Please, indicate on a scale from 1 to 7 your attitude towards the following statements, where

\begin{tabular}{|ccccccc|}
\hline $1=$ & $2=$ & $3=$ & $4=$ & $5=$ & $6=$ & $7=$ \\
\hline $\begin{array}{c}\text { Strongly } \\
\text { agree }\end{array}$ & $\begin{array}{c}\text { Somewhat } \\
\text { agree }\end{array}$ & $\begin{array}{c}\text { Slightly } \\
\text { agree }\end{array}$ & $\begin{array}{c}\text { No } \\
\text { opinion }\end{array}$ & $\begin{array}{c}\text { Slightly } \\
\text { disagree }\end{array}$ & $\begin{array}{c}\text { Somewhat } \\
\text { disagree }\end{array}$ & $\begin{array}{c}\text { Strongly } \\
\text { disagree }\end{array}$ \\
\hline
\end{tabular}

\begin{tabular}{|c|c|c|}
\hline 1. & $\begin{array}{l}\text { ever tell anyone the real reason you did something unless } \\
\text { is useful to do so. }\end{array}$ & $\bigcirc \bigcirc \bigcirc \bigcirc \bigcirc \bigcirc \bigcirc$ \\
\hline 2. & $\begin{array}{l}\text { The best way to handle people is to tell them what they } \\
\text { want to hear. }\end{array}$ & \\
\hline 3. & One should take action only when sure it is morally right.* & \\
\hline 4. & Most people are basically good and kind.* & \\
\hline 5. & $\begin{array}{l}\text { It is safest to assume that all people have a vicious streak } \\
\text { and it will come out when they are given a chance. }\end{array}$ & \\
\hline 6. & Honesty is the best policy in all cases.* & \\
\hline 7. & There is no excuse for lying to someone else.* & \\
\hline 8. & $\begin{array}{l}\text { It is hard to get ahead without cutting corners here and } \\
\text { there. }\end{array}$ & \\
\hline 9. & $\begin{array}{l}\text { All in all, it is better to be humble and honest than } \\
\text { important and dishonest.* }\end{array}$ & \\
\hline 10. & $\begin{array}{l}\text { When you ask someone to do something for you, it is best } \\
\text { to give the real reasons for wanting it rather than giving } \\
\text { reasons that carry more weight.* }\end{array}$ & \\
\hline 11. & $\begin{array}{l}\text { Most people who get ahead in the world lead clean, moral } \\
\text { lives.* }\end{array}$ & \\
\hline 12. & $\begin{array}{l}\text { Anyone who completely trusts anyone else is asking for } \\
\text { trouble. }\end{array}$ & \\
\hline 13. & $\begin{array}{l}\text { The biggest difference between most criminals and other } \\
\text { people is that criminals are stupid enough to get caught. }\end{array}$ & \\
\hline 14. & Most men are brave.* & O \\
\hline 15. & It is wise to flatter important people. & \\
\hline 16. & It is possible to be good in all respects.* & \\
\hline 17. & $\begin{array}{l}\text { Barnum was very wrong when he said that there's a sucker } \\
\text { born every minute.* }\end{array}$ & \\
\hline 18. & $\begin{array}{l}\text { Generally speaking, men won’t work hard unless they’re } \\
\text { forced to do so. }\end{array}$ & \\
\hline 19. & $\begin{array}{l}\text { People suffering from incurable diseases should have the } \\
\text { choice of being put painlessly to death. }\end{array}$ & \\
\hline 20. & $\begin{array}{l}\text { Most men forget more easily the death of their father than } \\
\text { the loss of their property. }\end{array}$ & 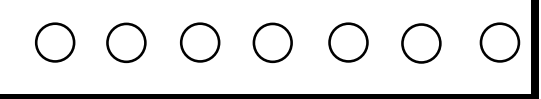 \\
\hline
\end{tabular}

* Statements opposing the Machiavellian principles are marked with an asterisk. 


\section{Appendix F}

Table 13 Summary of the Elicited Risk Attitudes

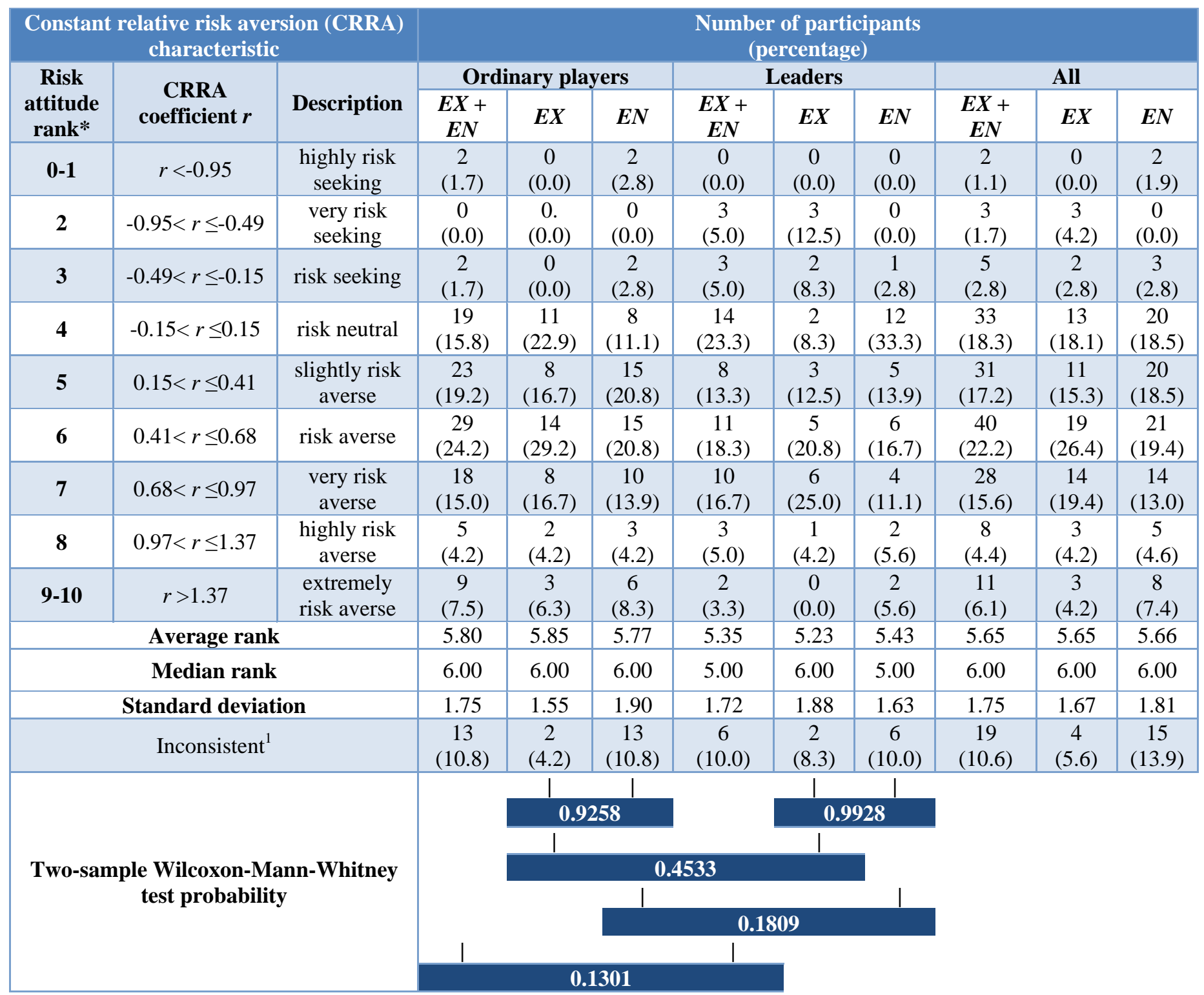

* Number of safe choices made in the Holt and Laury (2002) procedure.

\footnotetext{
${ }^{1}$ Inconsistent participants were excluded from the non-parametric comparison. In the econometric analysis,
} inconsistent participants were assigned a median rank. 